\title{
Exploring the Role of the Customer in the Fuzzy Front End of Innovation
}

\author{
By \\ Liam Harker
}

A thesis submitted to the Victoria University of Wellington in fulfilment of the requirements for the degree of Master of Advanced Technology Enterprise

Victoria University of Wellington 
Table of Contents

ABSTRACT

INTRODUCTION 3

BACKGROUND $\quad 4$

NEW VENTURE LITERATURE

THE FUZZY FRONT END

EFFECTUATION

\begin{tabular}{lr} 
RESEARCH AIMS & 8 \\
\hline
\end{tabular}

\begin{tabular}{lr} 
METHODOLOGIES & 8 \\
\hline
\end{tabular}

EXPLORATORY AND ITERATIVE RESEARCH

HYPOTHESIS TESTING

CUSTOMER ENGAGEMENT

PRODUCT MARKET FIT $\quad 10$

$\begin{array}{lr}\text { ITERATIVE DEVELOPMENT AND PIVOTING } & 10\end{array}$

SYNOPSIS $\quad 10$

NACRE $\quad 10$

$\begin{array}{ll}\text { SOUND CONCEPTS } & 13\end{array}$

INDIVIDUAL ROLE IN THE ENTERPRISE $\quad 16$

THE FUZZY FRONT END AND MANAGING UNCERTAINTY 16

EXPLORATORY RESEARCH TECHNIQUES

PHONE INTERVIEWS

FACE-TO-FACE INTERVIEWS

ONLINE SURVEYS $\quad 20$

DATA TYPES $\quad 20$

RELATION TO MY DISCIPLINE $\quad 21$

ENTERPRISE DEVELOPMENT 23

METHODOLOGY 23

Challenges $\quad 25$

PROJECT CHAMPIONS

COMMERCIAL V. EDUCATIONAL OUTCOMES

CUSTOMER V. MARKET LED $\quad 29$

$\begin{array}{ll}\text { UNCERTAINTY } & 32\end{array}$

\begin{tabular}{lr} 
CONCLUSION & 34 \\
\hline
\end{tabular}

BIBLIOGRAPHY $\quad 36$ 


\begin{abstract}
The early stages of development for new advanced technologies are notoriously difficult to navigate and manage effectively in such a way that leads to successful commercial application. This paper explores how the use of flexible and exploratory frameworks based in customer engagement can provide valuable insights into how advanced technologies can be developed to solve validated market problems. The paper reflects on the challenges faced and lessons taken from our practical experience using this approach to develop advanced technologies emerging from within Victoria university of Wellington.
\end{abstract}

\title{
Introduction
}

The master of advanced technology enterprise program has a strong focus on building multi-disciplinary teams that can draw on their combined skills to build new advanced technology enterprises. For each of us in the team, this meant drawing on elements of our backgrounds to piece together frameworks that could be used to understand the new landscape of technology enterprise we had entered into. There were of course gaps in our knowledge as a team, and we attempted to fill these with works from both the academic world and of practitioners within entrepreneurship communities. This unconventional mixture of frameworks helped us to develop a holistic view of the difficulties that face many new technologies in their development and provided us with methodologies to navigate this often overwhelmingly complex process.

The following is an account of how we applied these frameworks to emerging new technologies from research departments within Victoria University. It covers the activities we engaged in and frameworks we explored as we sought to effectively develop real world applications for these technologies. It also reflects on the many challenges and barriers we faced in trying to achieve this goal, from managing stakeholder relationships to developing disruptive technology applications. 


\section{Background}

New venture literature

\section{The fuzzy front end}

Having come from a discipline in biotechnology, much of the knowledge I possessed had little to no application in the process of commercializing new technologies. One area that did share common ground however, was the concept of the 'fuzzy front end', a term used in new product development to describe the initial and uncertain stage of new technology development.

The term 'the fuzzy front end' was popularized by Smith and Reinertsen in their 1991 article titled 'shortening the product development cycle'. It is intended to describe the first stage in new product development, between the conception of a new idea and the point in time when that idea is judged ready for further development or termination (Kim \& Wilemon, 2002).

The fuzzy front end has recently generated increased interest amongst research groups as one of the more effective places to improve efficiencies and success rates in the new product development process (Kim \& Wilemon 2002). Research has shown that organizations that are able to navigate this process more effectively have higher rates of success in later stages of the produce development process. (Cooper \& Kleinschmidt 1988). The organizations that are able to navigate the fuzzy front end more effectively often do so by focusing on well-defined projects and product requirements before progressing on to the development stage. (Robert G. Cooper 1990; Kim \& Wilemon 2002)

The benefits for better project and product requirements are not only a higher product success rate but also a reduction in unsuccessful projects that would otherwise consume resources as they are slowly phased out later in the product development process (Kim \& Wilemon 2002).

In spite of this evidence however, research has shown that only $6 \%$ of capital used in the new product development process is spent on activities at the fuzzy front end (Cooper \& Kleinschmidt 1988). Based on this research it is has been suggested that even small improvements and a greater allocation of resources in the approach to the fuzzy front end 
of new product development could bring significant benefits to the new product development process.

A large part of why the fuzzy font end has attracted this level of interest is that it is one of the few areas of the new product development process that has not undergone formalization. (Khnurana and Rosenthal, 1997). The fuzzy front end by its very nature is unroutine, dynamic and uncertain, properties that do not lend themselves well to highly structured processes. For this reason, a universal approach to navigating the fuzzy front end has proven difficult to develop (Verworn \& Herstatt 1999).

In contrast to the fuzzy front end, formalization has occurred in almost all other areas in the new product development process. This has been bought about most commonly through the implementation of stage-gating systems, which are designed to periodically screen projects as they pass through the product development process (Ettlie \& Elsenbach 2007).

While it can't be argued that the implantation of formalized stage-gate frameworks to the new product development process has not produced significant improvements to commercialization activities, they still have areas of weakness when addressing the fuzzy front end. Often these frameworks are criticized for being "too time consuming, with too many time wasters, too bureaucratic, and having no provision for focus" (Cooper 1994). In response to this criticism many large companies that use formalized stage-gate processes have been trending towards more flexible and 'fuzzy' approaches to new product development (Cooper 1994).

This research suggests that approaches to the fuzzy front end including the stage-gate processes as they currently are, lack the flexibility to address the unorthodox nature of the fuzzy front end. In order to improve efficiencies and success rates in the fuzzy front end, new approaches that can accommodate these factors will need to be adopted.

\section{Effectuation}

One such approach that allows for more insights into the fuzzy front end is the process of effectuation. Effectuation is a theoretical framework designed to capture the decision 
making process used by many successful entrepreneurs to navigate commercial opportunities with high levels of uncertainty (Sarasvathy 2001).

The theory of effectuation represents a movement away from the study of entrepreneurship by the personal traits of entrepreneurs and instead looks at their actions and the decisions they make as a means to understand entrepreneurial activity.

Effectuation logic was first documented by Sara Sarasvathy through extensive interviews with top performing entrepreneurs, combined with observation of specially designed decision-making exercises (Sarasvathy 2001). A key finding from her research showed that entrepreneurs take a fundamentally different approach to navigating situations of high uncertainty when compared to more traditional methods (Sarasvathy 2001).

Typically, the traditional approach to opportunities with high levels of uncertainty is to make informed predictions about what a market will want in the future and aim to create a product that will meet that need (Perry 2012). This type of thinking follows the logic "to the extent to which you can predict the future, you don't need to control it" (Sarasvathy 2001).

Entrepreneurs using effectuation logic, instead, look to what they can control when determining if an opportunity should be exploited. By getting a customer to commit to buying a product before it is built for example, the entrepreneur has significantly lowered the risk that the product they are building will not meet the needs of its customers. This type of thinking follows the logic that "to the extent you can control the future; you do not need to predict it" (Sarasvathy 2001).

To illustrate the difference between these two approaches, Sara Sarasvathy uses an example of two chefs asked to prepare a meal at a guest's home.

The first chef will take the more traditional approach to uncertainty (which Sarasvathy has labeled 'causation'). In this approach the chef picks out a recipe for the dish they will prepare and sets about shopping and collecting the ingredients needed to cook that meal. In the words of Sarasvathy "It begins with a given menu and focuses on selecting between effective ways to prepare the meal" (Sarasvathy 2001).

The second chef will use an approach based on effectuation when preparing the meal, they look through the cupboards of the kitchen for possible ingredients that can be used to 
create a meal. In this scenario they have to imagine all the different possibilities using these ingredients, then select a meal and cook it. Again in the words of Sarasvathy "It begins with given ingredients and utensils and focuses on preparing one of many possible desirable meals with them" (Sarasvathy 2001).

To achieve a focus on control rather than prediction, entrepreneurs using effectual thinking have been shown to share five fundamental practices (Sarasvathy 2001). Entrepreneurs exhibiting effectual thinking will:

- Start with what they have, not what they want to build.

- Focus on affordable loss, not profit that can be gained.

- Cooperate with those they can trust, seeking out pre-commitments.

- View the unexpected positively, surprises can show new opportunities.

- Recognize that they cannot control the future but some aspects of it are within control.

These five practices all function to reduce the overall risk that an entrepreneur is exposed to even in situations of high uncertainty.

Research into the area of opportunity recognition and selection, has determined that those practicing effectual thinking "will outperform individuals who rely on a more straightforward exploitation of their current knowledge base" (Corbett 2007). This is believed to be the case as users of effectual thinking will interact with a market and grow their knowledge of an opportunity, while those who do not use effectual thinking will typically rely on existing knowledge they already possess to exploit opportunities (Corbett 2007).

The effectuation process outlined in Sarasvathy's research gives some strong insight into the potential reasons why traditional approaches to the fuzzy front end perform so poorly. Rather than growing knowledge around the market opportunities presented by new technologies, organizations using causational approaches in this early stage of development, focus on the existing knowledge they possess to evaluate opportunities. 
Both of these frameworks help to capture and explain the importance of the fuzzy front end of technology development and how it impacts on later stages of new product development success. They also highlight a need for more flexible approaches to the fuzzy front end in order to improve successful opportunity selection of new technologies.

\section{Research Aims}

This paper aims to explore how more flexible frameworks based in exploration of customer and market, can be applied to the high levels of uncertainty in the early stages of new product development of advanced technology enterprises.

\section{Methodologies}

\section{Exploratory and Iterative research}

Based on our research of the fuzzy front end and Sara Savasvathy's effectuation principles, we looked for methodologies that were exploratory and flexible in nature. We sort methodologies that could be used to engage with a market and gather the detailed knowledge we required to successfully navigate the uncertainties of the projects we worked with.

Given the entrepreneurial focus of Sarasvathy's work and the limited resources available to us as a team, it made sense to look for these methodologies within the start-up community. We settled on the works of Blank, Adams and Ries, practitioners within the entrepreneurial community that focus on very practical, iterative and exploratory market research methods as a basis of developing in new products and ventures.

These works all shy away from traditional product development methods stating they are often ineffective and frequently allocate resources to organizational challenges rather than addressing the real source of failure, market uncertainty (Adams 2010; Ries 2011; Blank 2006). In fact Adams goes so far as to contribute $85 \%$ of all product failure to market uncertainty and misunderstood customer needs (Adams 2010). This group advocates for an alternate approach to market validation rooted in primary market research, instead using in 
depth customer engagement to understand the needs of customers before ever creating a product.

Gathering this primary market data up front, before producing a product serves two purposes. Firstly, it provides valuable insights into how a product will be received by a market and its customers. If there are significant problems in how the product on meets their needs, then it can be identified before spending unnecessary resources on creating prototypes and product runs (Adams 2010; Blank 2006). Second, if an initial product does not meet the needs of customers then the in depth knowledge and understanding of a market gained by engaging with customers can be used to change the product to better meet the needs of these customers or to find another market with needs that fit better with the attributes of the technology. This process of changing elements of the product or the market it is applied to is popularly known within the startup community as pivoting (Ries 2011).

When establishing a methodology, we used elements of the iterative and exploratory process put forth by Blanks, Ries and Adams, which can summarized into four key components:

\section{Hypothesis testing}

Hypothesis testing is about turning hypotheses into facts (Blank 2006). According to Blank, early stage technologies and startups must acknowledge that all they start with are a number of untested hypotheses about their product and market, called assumptions(Blank 2013). These assumptions could range from whether or not customers are willing to pay for a technology through to the ability of the technology to perform as required. Hypothesis testing functions to validate that each of these assumptions is true before progressing on and building a product and business.

\section{Customer engagement}

Both Blank and Adams advocate for an approach called customer development or customer engagement to test these hypotheses. This approach involves talking to potential users, purchasers, and partners of a product for feedback on all aspects of the technology and its business model (Blank 2006; Adams 2010). Then using this feedback to revise the assumptions that the technology is based on, discovering which are true and which need to 
be corrected (Blank 2006; Adams 2010).

\section{Product market fit}

Product market fit is the confirmation that a technology or service satisfies a specific problem or need of customers to the extent that they are willing to pay for it (Adams 2010). This is generally identified in these communities through the previous concept of customer engagement, by taking the concept or a prototype of the solution to the market and getting their input before progressing to building it on mass. Early commitments by customers in the market can be good indicators of product market fit (Adams 2010)

\section{Iterative development and pivoting}

During this process of hypothesis testing and customer engagement, the aim is to find a viable application of the technology that will solve the needs of customers, and achieve product market fit. If customer engagement reveals the current product doesn't have product market fit then a new hypothesis for a successful application must be made and tested until a successful one can be reached. This process of applying new hypotheses and testing them becomes an iterative cycle until a viable outcome is reached (Blank 2006; Blank 2013; Adams 2010; Ries 2011). This may involve changing elements of the technology or changing markets many times to achieve success.

\section{Synopsis}

A core component of the master of advanced technology enterprise program was to have students working on real and emerging technologies from research originating from within Victoria University. To facilitate this, four researchers from within the university pitched technologies they had developed from their research to the master of advanced technology enterprise cohort, in doing so they outlined how each technology might be applied to a market that they saw had a need for their technology.

\section{Nacre}

From this, the technology we first selected was synthetic nacre, a biomimetic material produced by professor Kate McGrath of the school of chemical and physical sciences. "Biomimetics is the imitation of nature for the purpose of solving complex human problems." (Centre for Biomimetics 2006) In this case, synthetic nacre is an 
imitation of the natural process used by some mollusks to produce the inner layer of their protective shell. Nacre is more commonly known by the name 'mother of pearl' and one of its better-known forms is in the highly valued pearls grown by oysters throughout the Pacific Ocean.

Synthetic nacre has a number of attractive properties including high strength and biocompatibility that makes it an attractive candidate for an application within the medical industry. The potential use for nacre to aid in bone implants was one of the long-term goals for the new material.

We focused on an early stage application of this material within veterinary dentistry. It was thought that by creating a paste using ground Nacre mixed with a thermosetting gel, that the resulting product would be highly effective when filling cavities in the gums of animals following a tooth extraction. Doing so would reduce the chances of infection following the procedure, limiting the number of animals lost to complications as a result of this procedure.

We began by investigating the role that cavities of the gum played following tooth extraction and what rate of infection was caused by this procedure. The agricultural market is one of New Zealand's largest, representing \$14.8 billion in exports to the New Zealand economy (Brazil 2008). Given the vast number of stock animals in this market we started our investigation here. At this stage we had not yet developed a strategy for how we engaged customers and gathered information, for this reason these initial interactions were highly informal and un-routine. We contacted seven veterinarians with specialties in agricultural animals including cattle, horses and sheep. We also engaged several industry experts to provide insight on the use of materials to fill the cavities left in the gums following a tooth extraction.

The responses we received from these individuals strongly indicated to us that tooth removal in the agricultural sector did not occur regularly and on the rare occasions that it did, the cavity was simply sutured closed. The primary reason for this was put down to the diet of the animals and the way in which new teeth grew to fill gaps along the jaw making an implant not only impractical but almost impossible. 
We choose to move away from this initial focus following these discoveries; it was clear to us from the responses that we had gathered that there was not a strong need to fill cavities resulting from tooth extraction in agricultural animals.

Though our interactions, several of the experts we spoke with had suggested we explore the same cavity market for companion animals. They stated that companion animals have dental problems that are much closer to those of humans when compared to horticultural animals and longer life spans requiring more specialized dental care.

Having discounted a need for this application of nacre in the horticultural sector, we shifted our focus to the companion animal market for dental fillers. Once again we sought to talk to customers and experts within this market, contacting seven veterinary specialist across New Zealand.

Through these interviews we discovered that while tooth extractions were somewhat common in companion animals, the solution that most vets in this area used was to simply suture the cavity closed as the wounds of the mouth reportedly heal very quickly and do so without complications of infection. We found if a filler material was used, it was due to some form of bone loss or fracture where the main function of the filler wasn't to prevent infection but instead to aid in the healing of bone. The materials used in this situation are known as bone grafting substitutes and have uses not just in dentistry but throughout the body in orthopedics.

At this stage we moved away from using nacre as inert filler and towards the possibility of using nacre as a bone-grafting substitute to treat fractures and bone loss in animals.

We had learnt from our initial talks with potential customers that the bone graft substitute market was saturated with a variety of different products seeking to provide a synthetic bone graft substitute solution. It was clear from conversations with veterinary orthopedic specialist there was the need for a synthetic bone grafting material in the market that could achieve the same result as native bone. Bone grafts taken from with the animal itself, called autografts, are still the preferred material for bone grafting due to its effectiveness over synthetic products. Autografts however did require additional surgery and healing time as a result of having healthy bone removed from a separate part of the body to form the 
autograft. Further research determined that a bone grafting material made using nacre, would enter the market as a 'me too' product as the properties of nacre did not give it distinguishable features over the many synthetic bone grafting materials already on the market.

The key missing feature between synthetic and native bone grafting materials was a property called 'oesteoinductivity' - this is the ability of the material to induce new bone growth at the site of implantation to allow for complete healing of the bone. Currently no synthetic material has been able to successfully achieve oesteoinductivity in the body at a reliable and safe level.

It was decided that without a way of showing oesteoinductivity in nacre, creating a product for this market would be unwise as it would have no strong point of difference. Instead focus shifted back to the technologie, we had discovered evidence in the literature that nacre may be able to act as an oesteoinductive material. If this were the case then nacre could have a significant opportunity to make an impact on the synthetic bonegraft market. To test nacre for osteoinductive properties the technology was handed back to researchers to conduct further testing using cell lines. Following a positive results here it is hoped that commercial development can continue towards an application in the synthetic bone grafting market.

\section{Sound concepts}

Sound concepts was developed by Natasha Perkins from Victoria Universities School of design and focused on the addition of 3D form to a range of acoustic baffling materials by a process of heat pressing. The addition of this 3D form was hoped to improve the acoustic benefit already possessed by these materials. Typical acoustic materials rely on absorption as a means of dampening sound. While the addition of 3D form promised increased deflection and the passive distribution of sound. These properties combined were thought to have a greater acoustic benefit than just the absorptive properties alone.

Sound Concepts was originally designed to meet the need for better acoustics in the classrooms of primary and secondary schools. Class rooms in New Zealand (and abroad) notoriously have bad acoustics and several links had been made comparing high noise levels to poor performance in the classroom (Ministry of Education 2007). 
We recognized early on that there were multiple stakeholders in this market. While school classrooms were the ultimate customer, they relied on the knowledge of architects and designers to make the choices on which materials to use when fitting out classrooms. Acoustics is a very specialized area of architecture and often required the input of acoustic engineers to provide additional expertise. To address each of these separate customers or influences we split our customer/market engagement across each.

\section{Schools and classrooms}

While it was obvious to us from research we had conducted that schools did have a problem with acoustics, it needed to be determined why they were not solving the problem - was it due to the lack of a solution, lack of funds, or both.

Schools were approached in the same manner as above, a set of questions was built to gather information on the current use of acoustics in classrooms and the perceived need for new solution and the requirements for these.

Feedback from these surveys told us that that the main barrier to improving acoustics within classrooms was budget restrictions. Public schools are government funded and can only allocate so much of this funding to improvements and other areas often had a higher priority than acoustic treatments in classrooms.

\section{Acoustic engineers}

An important part of exploring the sound concepts project was gaining an understanding of how acoustics was approached by experts, what properties of acoustic materials were important to them and how these products were chosen. We approached this by contacting seven acoustic engineers with backgrounds in architecture projects and asked them question surrounding the above information.

What we quickly discovered and confirmed through these conversations was that while absorption of noise was very important in the selection of acoustic materials, the ability of the material to disperse sound using 3D form was not something that was even considered when acoustic engineers provided information to architects on which materials to use.

\section{Architects}


The information gained from engagement with architects provided valuable insight into the acoustic treatment of spaces and allowed us to correct some of our assumptions surrounding how the problem of noise was addressed in large open spaces.

The main focus of engagement with architects was to gain an understanding of how they resolved problems of acoustics in architectural projects they worked on. We initially focused on classrooms but quickly shifted focus to open plan offices after discovering that public schools had budgets that made this market unviable for the time being. What the data showed was that the solutions most commonly used by architects were very simple approaches such as basic carpet and industry standard ceiling tiles that offered a low level of acoustic baffling. When we asked about specialty materials we found that only a small number of projects used these and they were often created on a bespoke basis. However the major discovery came from the information that the majority of noise related solutions were not material based and instead relied heavily on human behavior changes using objects like furniture to create areas of quite or privacy where longer conversations and meetings could take place away from areas where individuals need to concentrate.

Using this feedback we made the decision to shift our focus to the need for better acoustics in open plan offices. The decision to focus on offices was influenced by the data collected during the investigation into acoustics in schools. It was recognized that schools and offices shared a similar problem, having larger numbers of people in a shared space often creates high levels of noise which can be distracting. Unlike schools, open plan offices also have more resources to address the problem.

The engagement of customers in the open plan office space showed that there was indeed a problem with distraction and acoustics. In fact noise levels were one of the highest complaints of workers within open plan offices. Our data showed that generally open plan office managers relied on architects to provide acoustic treatment of a space rather than addressing the problem themselves. They would however, engage in furniture placement to help create collaborative meeting spaces that could be beneficial to encouraging the behaviors that lower noise in a shared space.

While we had confirmed a need for better acoustic solutions in the open office market, we had also determined that Sound Concepts as a product was not able to meet this need as 
the acoustic solutions this market was looking for were based in behavior changes not in better materials. For this reason we chose to move away from the technology of Sound Concepts and to instead focus on this new found market need and the solutions we could create to solve it.

\section{Individual role in the enterprise}

\section{The fuzzy front end and managing uncertainty}

As is discussed at length above, the fuzzy front end of the product development process is characterized by early stage projects with high levels of uncertainty. The two technologies we took on to develop were each at very early stages of development with equally high levels of uncertainty. Each was the result of academic research the inventors believed to have commercial applications within chosen industries. The technologies also had significant levels of uncertainty surrounding both technological performance and market acceptance.

The technologies both differed from those that I had been involved with previously as the technologies I had worked on in the past had been based strongly in technological uncertainty. This time the majority of uncertainty came from the markets for these technologies. In this case the technologies themselves had been progressed much further than the understanding of their market application, the academics behind the projects had both already created prototypes to test market applications of their technologies. What needed to be explored in detail was how the market would react to the technologies and how the technologies would fit the needs of those markets.

To grow the understanding of the market, the role I took on within our team centered on exploring market needs for each technology. This meant that much of the activity I was involved with throughout the duration of the program was not related to my previous discipline in bioscience. In my previous discipline, much of the focus in assessing new projects was placed on the technologies themselves rather than the market they were aimed at. There were several reasons for this, partly that many applications of bioscience technologies are in life saving technologies where the need by the market is taken as given. But also, much of the development in bioscience is done by large organizations that still use traditional approaches such as stage gating, that does not place as much emphasis on early 
stage customer exploration (Pisano 1990)

Typically in previous market research I had been involved with, the focus had been on the use of secondary sources of information such as market reports and competitor analyses. This time around, the emphasis was on gathering primary data from the market to understand customer problems and needs and how technologies could provide solutions. As this was a new experience for me it required learning a new skill set based in how to engage a customers and gather information on specific market needs.

\section{Exploratory research techniques}

The methods we adopted in this initial stage of gathering primary market data were rooted deeply in the customer engagement approaches of entrepreneurs and exploratory research methodologies. The works of Rob Adams and Steve Blank served as 'beginners guides' in how to contact and engage with markets and customers in order to gain a clear understanding of their problems and needs. . The core approaches we focused on from Adams work included phone interviews, face-to-face interviews and online surveys. The suitability of these approaches to gather information differed significantly and we found that we settled on only two to guide the majority of our exploration

What follows is an account of my experiences applying each of these customer engagement approaches to the fuzzy front end and a reflection on how successful I found each of them to be:

\section{Phone interviews}

In my experience phone interviews were generally the most effective method for engaging customers and offered several advantages over other methods we trialed. One of the biggest advantages of calling customers is that it's very easy to find the contact details of people in specific industries by using tools like the internet or even industry call lists (Adams 2010). It is a relatively simple task to sit for a day and call through these numbers back to back collecting information and is much quicker than would be possible to visit and personally interview each person face to face.

There were often challenges to calling however; it was very common for a person of interest to be behind a receptionist or service desk when you first called. This often made it difficult 
to even reach the person you wanted to talk to, let alone ask them to answer questions. Looking back we adopted several approaches to get around this problem. Generally it was the small things that made the difference, surprisingly to us at the time, our long introductions about the university project we were working on and our request to ask their boss a series of 'quick' questions was not always met with a great deal of enthusiasm and it was more often than not that our number would be taken and we would never hear from that person again. It was only when we changed our approach slightly that we started making progress, two things generally worked in my experience. The first was to ask for the person I wanted to talk to with no reference to what I wanted to talk to them about and very importantly to only use their first name. Looking back I think the reason this worked was the that by revealing that we were from a university and doing research we let them know that the person we were asking to talk to was not expecting our call and that our intention was to interrupt the person by asking them questions that were likely not highly important to the them. Instead, asking for the person by only their first name implies some familiarity and more often than not the call would be transferred straight through without any questions regarding what we were calling about.

The second approach that often worked well was to give our introduction about the project we were working on in reasonable detail to the receptionist and then instead of asking specifically for an individual, ask them if there was anyone at the organization that might be able to help us by answering a few questions on the project. This frequently worked well and only a handful of times did we get turned away. From my point of view I think the reason this worked so well was that it shifted the receptionists focus from "should I be letting this call through" to "who would be the best person to give this information". By shifting the focus in this way we were able to recruit the knowledge the receptionist had of the organization and its team members and use it to find the best people to talk to. Often this person was not the individual we had picked out and had a role in the organization that was much more relevant to our project.

Getting past gatekeepers is only one element of the process, however, it was generally the biggest barrier to accessing the people we wanted to speak with. More often than not once we were able to speak with the individual we were looking to contact, explained our project and what we were looking to find out they were more than willing to answer questions for 
us. Upon reflection I suspect that being students may have helped us in this area and allowed some of our smaller mistakes to be overlooked. It is my feeling that had we not mentioned that we were students the reception we got from people would not have been nearly as friendly and understanding.

\section{Face-to-face interviews}

While it's true that the majority of our interviews with potential customers were conducted via phone calls, we recognized very early on that face-to-face interviews often returned much more and much better quality information to the questions that we were asking. I believe this can be put down to two things, firstly the average length of an in person interview is much longer than a phone call. This longer time frame allows more time to be spent examining each question, asking subsequent questions on the information gathered and also builds better rapport with the person, making them comfortable and willing to share more information (Blank 2006; Adams 2010; Ries 2011).

Secondly it is my experience that the majority of these face to face interviews will happen at the person's place of work. This can have some real benefits when asking questions, many times if a question is asked of the person and they cannot answer it they will go and get another person from the organization that can, and bring them into the meeting. This can offer a whole new and often more specialized perspective on the questions you are asking and are more often than not is hugely beneficial.

We were also able to present information to potential customers in face-to-face meetings that we could not have do over the phone. We used this approach to show customers a later stage prototype developed by the group in order to get feedback on its suitability to their needs. this was something that could not have been done over the phone or in an online survey as it required customer to interact with the physical product.

Lastly on face to face interviews, the relationships that are built with customers are much stronger than those formed over phone and often meant we were able to come back to that person as the enterprise developed and ask them follow up questions or get their feedback on our latest developments. 


\section{Online surveys}

Throughout the process we also experimented with an online tool called 'survey monkey' which we used to construct surveys that could then be sent out to individuals via email. It was my experience that these were not an overly effective means of gathering the information we were searching for. While this approach would have saved us a great deal of time and effort, it lacked the personal connection that in my opinion was a major driver for people agreeing to answer our questions. We experimented with sending these surveys out via email and had a very poor response rate. I would speculate that the reason for this came down to the fact that an email is far easier to ignore than a phone call, it does not demand an immediate response in the same way that a call does, and so the individuals that received our email could easily dismiss the survey or mark it as something they will do later or 'when they have time'. The people receiving these surveys more often than not didn't know who we were and seemed unlikely to be driven to complete a survey for the benefit of a stranger, even if the work is in an area that might be relevant to them.

What we also discovered through experimentation with the surveys that people did fill out was the information gathered was of limited us to us anyway. Online surveys are effective in gathering quantitative data but we found that they produced poor results when use to collect qualitative data. In these earlier stages of customer engagement we found that qualitative not quantitative data gave us the best insight into the problems that potential customers where looking to solve, we were scanning the market and exact numbers were not overly useful at this early stage.

\section{Data Types}

It is worth mentioning that the type of data we looked to gather played a big part in the type of customer engagement we found to be most effective. The three approaches can be looked at as increasingly in depth methods of collecting primary market data. Surveys are good for wide scale customer engagement as the cost of conducting then is relatively low and they can be distributed to a wide range of customers very easily. We found surveys very useful when collecting specific and quantitative data relating to things like the amount of procedures that a veterinarian might conduct in a month. We found that they are not so effective when looking for qualitative data from customers, 
this type of data gathering is often non-specific and requires that follow up questions are used to clarify and refine responses.

In our experience phone calls and face-to-face interviews were much better suited to the gathering of qualitative data as the individual can provide more clarification to their answers and the data being collected can be done more flexibly as to explore new areas of interest in the conversation as they arise (Adams 2010).

\section{Relation to my discipline}

Prior to this experience, my understanding of how to address uncertainty was heavily based in the use of prediction, using resources like forecasting and market reports. I spent significant periods of time gathering this type of information from secondary sources with the goal of forming a clear and holistic picture of the markets we were exploring. Interaction with the market and customers at the early stages of technology was often actively discouraged to protect IP from accidental disclosure.

The approach we took this year was almost the polar opposite to this approach, rather than focusing on existing and secondary data to make judgments and assessments for new technologies, we used primary research techniques - interviewing potential customers for the technology from day one. The use of early stage customer engagement in this manner has shown me the insights gained by talking to the market early far exceed those that can be gained from secondary data collection when in the early stages of new technology development. This is not simply the case with the data that is gathered but also in the connections that are made within the industry and the opportunity to establish precommitments with real customers.

A take away form this experience has been the realization that technology should not be developed in the isolation of a lab or R\&D office or based on stock standard market reports and second hand knowledge as these methods fail to provide a holistic picture. New products aren't created in a closed room, interaction with markets breeds insights and opportunities that cannot be gained any other way.

This said, secondary sources of market data have their place in assessing the commercial opportunity for a technology. However my experience has shown me that this is generally most useful after engaging with customers. Secondary market data cannot tell you if 
customers will buy a product, only a customer can tell you this. What it can do is provide valuable quantitative information about aspects of that market like the size of a market opportunity. The point of this is not that primary or secondary approaches are more effective but that from my experience, a primary approach is better suited to the initial stages of exploration for a product and finding product market fit, while secondary sources can provide data that is better suited to addressing the scale of the market and not accessible via primary.

This can be seen in the experience we had with the development of nacre as a dental filler, the secondary marketing information we gathered showed us that there was a growing market in dental care for companion animals and a number of competitor products already existed in the dental filler space. Both of these pieces of information could be interpreted to suggest that their was a future market for a product here. Contrary to this, what we found after talking to experts and practitioners in this space was that in fact not only was there almost no need for product like this but that the products that did exist were not considered to perform well at all and practitioners frequently turned to more effective alternatives.

My previous discipline of bioscience enterprise has the potential to benefit greatly from the application of these approaches to the exploration of new technologies. Biotechnology is an industry that has traditionally been dominated by large companies seeking to capture the entire process of product development from the research and drug discovery right through to the distribution and sales(Pisano 1990). There has been a segmentation of this market in recent times, as large companies have failed to deliver new products and approach patent cliffs as their current technology rights expire (Pisano 1990), these companies are now increasingly turning to the acquisition of startups that have done the work to de-risk and validate new technologies (Pisano 1990). The kind of early stage technology validation that we conducted this year has the potential to offer real value through technology startups that can be used to validate technologies before being sold to companies that have the vast funds and resources needed to capitalize on them.

However within this it needs to be recognized that parts of the biotech market differ in their problems of uncertainty from those of other technology applications. Drug discovery being the biggest exception, where the market need for new treatments is so strong it is obvious 
and does not require in depth primary research to understand - a good example of this is the need for new cancer drugs, cancer is one of the most widespread diseases in the developed world and the need for new treatments in this area is so great it can be considered obvious. In these cases the majority of project uncertainty will center on the technology and whether or not it can be shown to be both safe and effective.

Biotech isn't all novel drugs, however, and there are many applications of biotech that do not have such a certain customer need - platform technologies are a good example, how does a company decide which market to enter first when their technology has dozens of potential applications. In this case an understanding of the need for the technology in each market can be used to select attractive first candidate markets. Ultimately however, even in the case of novel drugs, the biomedical industry is an incredibly complex one and with a long list of customers before the product ever reaches the end user. Understanding the benefits of a drug to the person receiving a treatment is not enough, looking to the medical professionals administering the drugs, hospitals buying the drugs and insurance companies paying for the drugs, can be highly important in the success of a new biotechnology products (Damian Hine 2006).

All in all the role I took with the enterprise was very market facing, focused on interaction and engagement with customers to understand their needs and problems. The exploration of and exposure to different data gathering techniques has helped me develop skills that I believe will be highly useful once applied back to my specific discipline of biotechnology.

\section{Enterprise development}

\section{Methodology}

The main methodology that guided the team through the enterprise development process was the iterative and exploratory approach used by entrepreneurs. As is mentioned above, due to our restrictions in resource and small team size we chose to pursue the practices and frameworks of Steve Blank, Rob Adams and Eric Ries as our main approach to the development of our enterprise. 


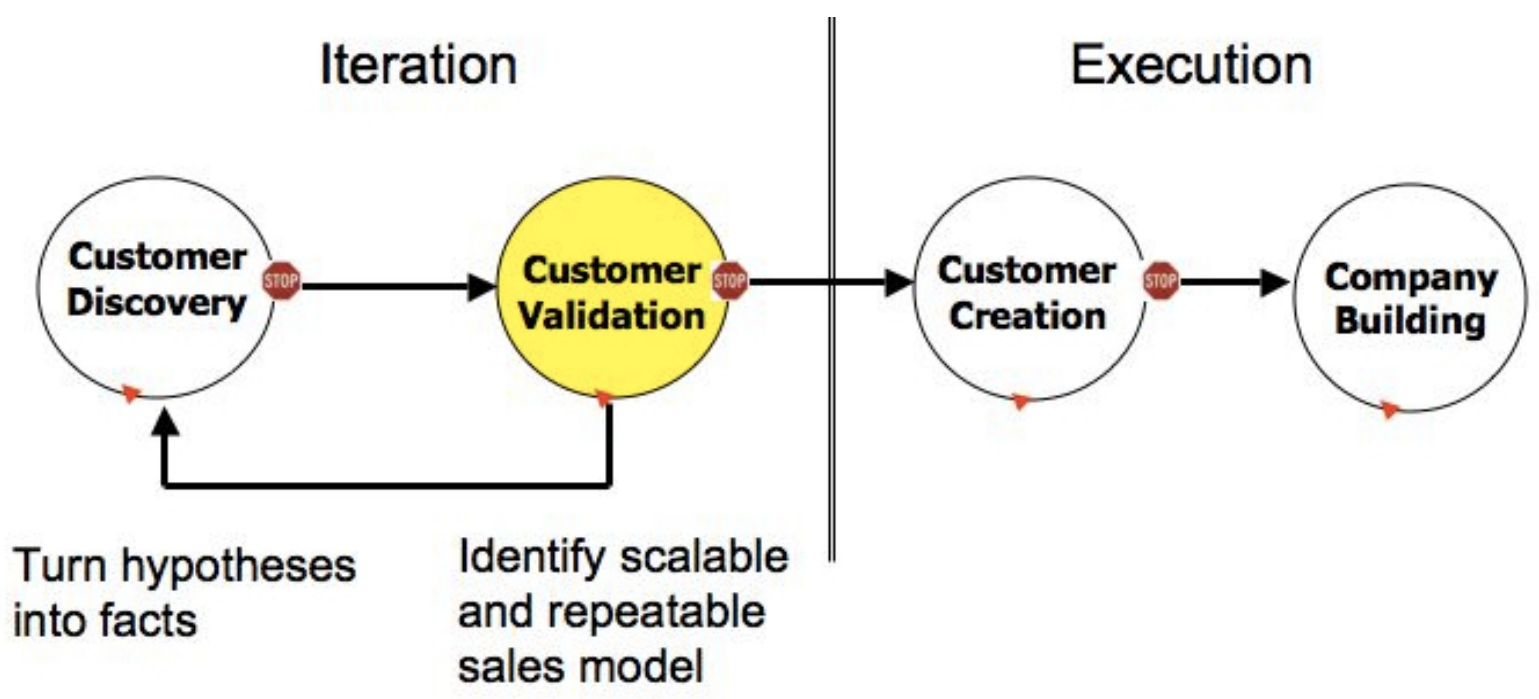

(Source: Four Steps to the Epiphany by Steve Blank, 2006)

This simple diagram above shows the iterative process of testing a product or service with its intended customer and how to use the results of this interaction to revise a product or service to better meet the needs of customers before moving on to production.

This process was more or less followed in developing both Nacre and Sound Concepts. For example, In the case of Nacre we started with the assumption that Nacre had an attractive application as a veterinary dental filler. We tested this assumption using customer engagement, talking to experts and veterinary specialists. This activity in turn told us that in fact the demand for a dentil filler in this market was negligible and that we would not be able to achieve product/ market fit . However, using this feedback and suggestions from experts we spoke with we recognized that the material had potential applications in the veterinary orthopedics market as a bone graft substitute. This type of hypothesis testing and iteration allowed us to move the technology from a veterinary dental filler with very little demand, towards the much stronger market need for a synthetic bone grafting material where customers were already actively looking for new products. We often felt that we were going in circles but each iteration bought us closer to a viable application of our technology.

Within this process there were much more complicated elements to be managed, below are some of the key challenges faced through our experience and an outline of how we addressed them. 


\section{Challenges}

\section{Project champions}

One of the more striking lessons I have taken away from this year has been the importance of managing stakeholder relationships in projects like these, with a particular focus on the project champion (inventor) of a technology.

Much of our interaction with the two project champions we worked with this year consisted of short and infrequent (once a month at most) progress meetings where we updated them with the work we were doing, where we had gotten to and they did the same. The unfortunate result of this arrangement was an undeniable feeling of disconnection between the two groups. While we were both working on the same project/technology, we were not working together towards a common goal or outcome. At times it felt to us that we were simply working on a market report for the team doing the research and developing the technology. I can't comment on the feeling of the project champions but I suspect that they would have felt equally disconnected from the work we were engaged in. Because of this disconnect we sometimes found it difficult to react to market feedback in a fluid and dynamic way because we didn't feel we had authority to change the scope of a technology without the consent of the project champion. This relationship made the work we were doing fell much more theoretical and we occasionally found it difficult to apply the information we found back to the technologies.

At the time, I don't think we fully realized the potential difficulty a relationship like this could cause in the development of the technologies. It limited discussion and collaboration between the two groups and created an underlying and unstated attitude of us and them during times of frustration.

Looking back at how this went, we should have pushed much harder for a closer relationship with the project champions we worked with. We had separated into two areas of expertise but had little to none of the communication that was needed between the groups to create something from it.

My feeling is that even more frequent meetings and information sharing between the groups would not have been sufficient to resolve this. In order for a relationship like this to 
function well, both groups must be involved in the entire process together, not as separate parts to a wider team. In this case the sum of partial understandings don't make a whole. A holistic view needs to be taken by each person involved that incorporates both knowledge of the market and the product.

While I was not content with the relationship we ended up having between ourselves and the project champions we worked with, I suspect that there are some quite honest and understandable reasons as to why it happened. I would speculate that an element of 'holding on' to the control of projects on the behalf of the project champion played a part and for good reason. As I understand it both the projects that we worked with were the product of multiple years of research by a dedicated individual who had taken ownership and driven the project to the point that it was at when we took it on. It is therefore understandable that when a group such as ours came along and quite separately did research that changed elements of the project or challenged the view that the project champion may have had, that the response was not of welcome and rather served to drive the two groups apart further. I can only speculate that this may have played a small part in the divergence of our two groups but it is an explanation that fits with some of what I saw over the year and in the reluctance to take on board some of the findings we made or in ignoring recommendations based on market feedback we had gathered. I see it as a failure on behalf of both groups but one that perhaps we should have learnt from the first time around and taken steps to avoid repeating with our second project.

I found that viewing this relationship through the lens of Sarasvathy's effectuation and causation also helps to make some sense of the situation. Ultimately each group had different views of what we were trying to achieve with the resources we had. Viewed this way, it could be argued that the academics we worked with had much more of a 'causation' based mindset towards the projects development. They saw a finished product application for their technology and looked to collect the needed resources and expertise to create that product (the cavity filler of nacre and acoustic baffle of sound concepts). Much like Sarasvathy's chef example, they had the recipe for what they wanted to make and they were putting together the ingredients.

On the other hand as students we had an approach based more in effectuation, we were 
looking at the technology as part of a collection of resources and we were seeking appropriate applications that could combine these resources. In this case we are more like the second chef in Sarasvathy's example. We had a collection of ingredients and now we were looking at the possibilities for what dishes we could make. This is especially clear when looking at nacre and sound concepts. In each case we looked at how we could apply the resources at hand to a variety of different market needs. For nacre we looked at dental fillers, bone grafting materials and pearl seeding. In the case of sound concepts we looked at acoustics, aesthetics and partitions for offices and schools.

Regardless of which method was more appropriate for the situation, when viewed this way it's clear why there was a mismatch between the activities of the two groups and how a lack of communication between the two groups only exacerbated the problem.

In future I will approach the situation very differently, insisting that the project champions are more involved in crucial aspects of the customer engagement process will allow them to build up and change their perception and understanding of the market they have created for. Part of our role as a team should have been the facilitation of interaction between the project champions and critical market players, as to expand their understanding of how their technology could really impact on that market not the market that they believed or perceived to be there.

In summary, it is clear to me now that new technology development cannot be done in isolated groups. There absolutely must be a flow of information and expertise through one single team. A team must be working towards the same goals and outcome and adapt to new findings and challenges that occur. One of the major advantages small groups and startups have over larger organizations is the agility and maneuverability that comes with small size. Its important to utilize this and not fall into the trap of just doing 'your bit' and expecting everyone else to do theirs. Completing a prototype in the R\&D department and 'throwing it over the wall' to marketing does not lead to effective and innovative product development.

\section{Commercial v. Educational outcomes}

Balancing the outcomes of the year was something we struggled with both individually and as a team, coming into the course, we were pitched technologies with the aim of developing 
them as real opportunities. Within this however, we had academic outputs following our experience and individually we each had goals for skills development that we had each put on ourselves. We each saw the course as an opportunity to experiment with different approaches to commercialization and to learn a range of new skills. Balancing these goals caused friction at times and plenty of debate within the team.

The core of our conflict was illustrated well in the decisions we made to hand back or continue development of technologies as we progressed through the year. On more than one occasion we came to a point where there wasn't a strong need for the technology we were working with. At these points we were faced with two options; do we make the commercially orientated decision and drop the current project, go back to the drawing board and find a more commercially sound application with a better chance of success or; do we carry on with the project, even though we recognize it's a decision that we would not make in the real world but that by pursuing this smaller opportunity we will get exposure to a new skill set that we would not otherwise have an opportunity to develop.

At different stages throughout the year we made both of these decisions. With nacre we handed the technology back to researchers and choose to move on to a more viable project that had a more appealing commercial application. In the case of sound concepts however we did the opposite, choosing instead to pursue an application of the technology in a small market as a solution to the need for temporary collaborative work spaces in offices. This was a market we recognized was small and was not one we would have pursued had the enterprise been outside of the university program.

Ultimately we choose to develop a project that wasn't likely to end up being a disruptive and hugely innovative technology because we wanted to develop a particular set of skills and round out our educational experience. This was something that we were criticized for at our final presentation, and rightly so. The individual who provided the feedback did so from a commercial perspective and commercially the decision we made was not one we would have made in a purely commercial environment.

This was also an issue that we encountered on a level of commitment from the project champions. While I believe they had rather open views on what role the commercial world played on their research, it was still obvious in both instances that the academic world and 
the systems of accomplishment and reward that exist within it held high importance for them. While we never had to deal with any direct clashes between the goals we had for the technology in a commercial sense and the goals the project champions had in the academic world. It was something that we were aware of in both technologies we worked with. Drawing on the research practices within my discipline of bioscience, the academic performance system of achievement offers a probable explanation for the priorities held by academics. Due to the nature of this system, status and research funding within the academic world is heavily linked to publication records, while commercial successes resulting from research has little to no impact (Commonwealth of Australia 2000).

Obviously there are good reasons for this, namely that the system exists to promote innovative new research and not as a commercialization platform. This does however put more enterprising researchers in a difficult situation, especially when commercial development moves away from the focus of their research, as was the case in our project; sound concepts.

Its my view that conflict between commercial and educational outcomes we experienced was intensified based on the environment that we were in. The challenges of integrating commercial goals within an educational institute are not something that we are alone in facing, it is a commonly debated topic within the commercial communities and at a national government level (Narayan 2010). It is unlikely that this situation would be quite so pronounced in the commercial world. However if this was something I was confronted with again, outlining expectations and outcomes early on with all the stakeholders of the project would be one way in which I would approach the situation differently.

\section{Customer v. market led}

Possibly the largest challenge we faced this year was in where we took our lead from in order to develop the technologies we worked on. Within technology development their are two ways in which this can be viewed. Either through a product led approach or a market led approach, also known by the terms technology push (product led) or market pull (market led). Product led approaches put the product or technology at the core of development and seeks to find or create applications for that technology as it is, often looking at many markets for potential applications (Brem \& Voigt 2009). Market led of the 
other hand focuses on the need or problem of a market and its customers as core to development, seeking to create solutions to this problem by examining a variety of technologies and picking the ones that best meet those needs (Brem \& Voigt 2009).

The methodologies detailed above, that we used as a basis for our technology development were rooted strongly in a market led approach to technology development, advocating for a strong understanding of customer needs before producing products. This is evidenced by the high focus on customer engagement and testing that made up much of our activity throughout the program.

In contrast to this, the technologies we worked on were highly product led in their development prior to our involvement, with the project champions having chosen initial markets where they saw potential for their technology and built prototypes.

These two conflicting approaches, not surprisingly, caused friction as we sought to bring a balance of market and product approaches to the development of technology. As was the case with both technologies, the market feedback gathered on the initial products using the technologies did not support the original hypothesis for an application of the technology. The result of this was often a felling that we were on some kind of endless hunt for a viable application for our technology that no one seemed interested in.

We found that as we explored the markets of interest for the technologies and gained a better understanding of their problems and needs, that our approach transitioned from product led to one based more in the market. In the case of nacre this was evident in our actions following the discovery that its application as a dental filler was not viable. At first we sort to change the market that it was aimed at, moving from a agricultural animal focus to a companion animal focus. Later, however, when we were forced to change markets again we did so with more of a market led approach, gaining an understanding of the need for new and more effective bone grafting materials and looking at how nacre might be changed or improved to meet this need.

Ultimately as we experimented with these two different approaches we found that a market led approach worked better for us at such an early and exploratory stage of technology development. We found once we began investigating, that market needs are often more 
complicated they seem from an outside view. In the case of sound concepts the market need appeared simple at the outset, many large spaces that are shared by groups of people suffer from problems of disruption as a result of noise. The need for a product that could lower noise and improve acoustics seemed obvious. What we found out only after engaging and talking to the market was that, while this was true, reducing acoustics using materials was relatively ineffective and instead many architects were turning to furniture solutions to change the behaviors that caused much of the noise. This was an level of complexity within the market that we could not have known about without in depth engagement of customers and experts. This level of complexity makes it very difficult to select applications for a technology without having a comprehensive understanding of the market itself.

This said, I think it is important to realize, that while we did not find a product led development approach to be the most effective way find viable applications for new technologies, there was some merit in using the initial application as a starting point or vehicle for our exploration into markets and opportunities. Without the initial focus on the markets selected by the project champions we would may not have had the means or insights to explore the markets as we did.

While we found a market led approach to be more effective in developing the technologies we worked with we also came across challenges in how to best apply this approach. A significant challenge for us in our enterprise development was in effectively applying the methodologies we had adopted of exploratory and iterative development in a way that allowed us to develop applications that were disruptive in nature. One of the main criticisms of the use of market focused methods of development for new and innovative technologies is the tendency for these methods to shift technologies towards more incremental, rather than disruptive products (Paul Sloane 2011).

Historically disruptive innovations have reaped much higher returns than their incremental counterparts (Robert G. Cooper 1990) and so have attracted much attention in their commercialization approach. The argument for customer engagement being an ineffective method of developing disruptive innovations states that customers are generally unable to articulate future products that meet their needs before the products are developed (Brem \& Voigt 2009), the classic example is Henry Ford's comment, "If I'd asked customers what they 
wanted they have told me faster horses" (Cascio 2013).

We found as we applied our methodology of exploration and customer engagement, that on a whole, this argument was accurate - asking customers what they wanted didn't work, all they could suggest was slight improvements on the solutions they already had. In the case of Sound Concepts especially we found that this was the case, with customers suggesting solutions like different materials from which to make acoustic products.

The problem with this approach in my opinion was that it relies on a customer to come up with a new solution to their problem, while they have a personal knowledge of their problems as a customer they seldom have the capability to predict how now technologies might embody solutions to these problems. We found that rather the purpose of customer engagement or a market led approach was to gain an in depth understanding of the problems and needs a customer has and to apply our knowledge of new technologies to create new solutions for that customer or market.

The difference is subtle but makes a significant difference to the ability for market led processes to produce innovative and disruptive technologies. This was the approach we took with sound concepts, looking to understand not just the market need for acoustic products but also better ways of delivering acoustic solutions through changing behaviors.

\section{Uncertainty}

Uncertainty is a core feature of most new technologies and understanding how to navigate and reduce it played a huge part of our experience over the course of the program. Our approach to uncertainty changed dramatically over the year as we progressed from an unorganized and deskwork based method to the systematic application of customer engagement to the key areas of uncertainty within the technologies we worked with. Upon coming into the program the team was often overwhelmed by the shear volume of information we needed to collect and frequently fell back to long discussions as a group on how to approach this problem and vent our frustration. We initially spent long lengths of time exploring market reports on the industries we were interested in, trying to learn about and improve our understanding of specific markets. Ultimately in our experience this frequently led to more confusion, trying to learn the intricacies of an industry in such a short time frame meant that generalizations often had to be made. We would often form 
assumptions based on this information that led to a view of the market that, looking back now, was often generalised and naïve.

It wasn't until we adopted the exploratory and iterative research frameworks outlined in the methodologies section of this paper, that we began to develop more efficient and successful methods of navigating uncertainty. We applied elements of the iterative and exploratory approach outlined above to draw up hypotheses on areas of uncertainty we faced. We then tested those hypotheses by gathering information from the market in order to systematically reduce the uncertainties that we faced one by one.

Once we adopted an iterative and exploratory approach to making and testing hypotheses we were able to make systematic steps in reducing the uncertainty surrounding our technologies. A key takeaway for us that these methodologies and frameworks taught us, what that it wasn't practical, nor was it necessary, for us as a team to become experts in the specifics of the markets we were exploring, something that can be especially difficult and time consuming for markets that are highly technical. Rather, a better approach was to learn how to leverage the knowledge of the many experts already out there to explore how a product might create value and be used in that market (Adams 2010). Learning how to do this was a steep learning curve for all of us, and one we haven't mastered yet.

This approach allowed us to manage and reduce uncertainty from an overwhelming and intimidating experience to a series of steps that could be navigated in a straight forward way with the right input of time and resource. One of the biggest lessons was in that the way to address uncertainty was not internal discussion but rather, in the words of Steve Blank, we needed to "get out of the building" (Blank 2006) and find the answers by talking to the right people not by working them out for ourselves.

An important part of this too has been a change in mindset, relating to uncertainty, in the ability to become comfortable with a certain level of uncertainty without letting it overwhelm you or cause a conclusion to be drawn too early. The approach we followed does not deliver results immediately and often, during the process of exploring a market need, it can be easy to become despondent when you are being told that the market need does not fit with the technology being developed, as was the case early on in the program with various applications of nacre. If feedback from the market is contradicting the 
assumptions of an application of a technology then there is a great temptation to say, "We are totally off here, I'm done, let's walk away from this application and find a new one". Often we have found that persevering past that point can offer real rewards, even if it's just an insight into a different application for a technology in that market. It is also important to source feedback from enough people to form a well rounded view of the market and its needs, not just the needs of a few individuals (Adams 2010), but the number of people that constitutes a well-rounded view varies with the market. As a general rule of thumb we kept talking to customers until we were hearing the same information repeated several times from different people.

Above all, navigating and reducing uncertainty is a core component of developing new technologies and developing strategies to address this is crucial to their success. The strategies we applied allowed us to systematically address uncertainty as we developed the enterprise, helping us to guide development towards viable market needs with real customers

The experience of this program will undoubtedly have an impact on how I approach uncertainty in the future. It's obvious to me following this experience that uncertainty needs to be managed through frameworks and investigation. Debate and discussion within a team has its place and can be valuable tools, but if that discussion in not based on solid market validation then anything that comes from it can only contribute to uncertainty.

\section{Conclusion}

It has become clear from my experiences over the course of this program, that a more flexible and exploratory approach to the fuzzy front end of newly developed advanced technologies can provide valuable insights in the application of advanced technology. Providing a strong foundation for the more effective selection of successful advanced technology products.

This experience also revealed challenges in the application of a flexible and exploratory approach to developing advanced technologies, with particular reference to the importance of the involvement of project champions (or team members with technical roles) in the 
customer engagement process as a means to ensure the team is working towards a common goal that has been developed though credible sources. With this also came the importance of focusing on understanding specific needs and problems when engaging with customers and markets. Rather than simply asking the customer what it is they want, this strategy avoids the temptation to develop incremental solutions based on customer requests and retains the creative elements of product development allowing of a focus on disruptive applications of technologies that solve specific customer problems.

Above all the experience has shown me the importance of 'getting out of the building' and conducting primary market research with real customers to drive the development of new advanced technologies. Secondary market research of course has it place in the development of new advanced technologies, most notably in quantifying opportunities using data like market sizes or competitor analyses. We found however that generally secondary data provided an impractical approach to gaining an understanding of customer's problems and needs.

The complex process of developing new advanced technologies for commercial applications is likely to remain an ongoing challenge. While this exploration of the impact of exploratory and flexible approaches on the early stages of new advanced technology have provided insights into how the process might be improved, it still is far from perfected. 


\section{Bibliography}

Adams, R., 2010. If you build it will they come 2nd ed., Hoboken, New Jersey: John Wiley and Sons Inc.

Blank, S., 2006. The Four Steps to the Epiphany 3rd ed., Lulu.com.

Blank, S., 2013. Why the lean start-up Changes Everything. Harvard business review.

Brazil, S., 2008. New Zealand Official Year Book - Statisitics New Zealand,

Brem, A. \& Voigt, K.-I., 2009. Integration of market pull and technology push in the corporate front end and innovation management-Insights from the German software industry. Technovation, 29(5), pp.351-367. Available at: http://linkinghub.elsevier.com/retrieve/pii/S0166497208000898 [Accessed March 20, 2014].

Cascio, E., 2013. A Faster Horse? Customer, 31(12).

Centre for Biomimetics, 2006. University, Reading: What is Biomimetics?

Commonwealth of Australia, 2000. Research in the National Interest : Commercialising University Research in Australia,

Cooper, R.G., 1994. Third-Generation New Product Processes. Journal of Product Innovation Management, 11(1), pp.3-14. Available at: http://doi.wiley.com/10.1111/1540-5885.1110003.

Cooper, R.G. \& Kleinschmidt, E.J., 1988. Resource allocation in the new product process. Industrial Marketing Management, 17(3), pp.249-262. Available at: http://linkinghub.elsevier.com/retrieve/pii/0019850188900089.

Corbett, A.C., 2007. Learning asymmetries and the discovery of entrepreneurial opportunities. Journal of Business Venturing, 22(1), pp.97-118. Available at: http://linkinghub.elsevier.com/retrieve/pii/S0883902605000789 [Accessed February 25, 2014]. 
Damian Hine, J.K., 2006. Innovation and Entrepreneurship in Biotechnology, an International Perspective 2nd ed., Edward Elgar Publishing.

Ettlie, J.E. \& Elsenbach, J.M., 2007. Modified Stage-Gate. Product Innovation management, 24(585), pp.20-33.

Kim, J. \& Wilemon, D., 2002. Focusing the fuzzy front-end in new product development. $R$ and D Management, 32(4), pp.269-279. Available at: http://doi.wiley.com/10.1111/1467-9310.00259.

Ministry of Education, 2007. Designing quality learning spaces - Acoustics,

Narayan, A., 2010. The Role of Government towards Encouraging the Development of Academic Research Commercialisation in New Zealand Universities : A Historical Overview of Policy Directions The Role of Government towards Encouraging the Development of Academic Research Comm. N/A, (March), pp.1-34.

Paul Sloane, 2011. Why Customers Are a Poor Source of Radical Innovations.

Perry, J., 2012. entrepreneurial effectuation- a review and suggestions for future research.pdf. Entrepreneurship Theory and Practice, 36(4), pp.837-861.

Pisano, G., 1990. The governance of innovation: Vertical integration and collaborative arrangements in the biotechnology industry. Harvard Business School.

Ries, E., 2011. The Lean Startup, Random House Inc.

Robert G. Cooper, E.J.K., 1990. New Products: The Key Factors in Success, Marketing Classics Press, 2011.

Sarasvathy, S., 2001. Causation and effectuation : Toward a theoretical shift from economic ... The Academy of Management Review, 23(2).

Verworn, D.B. \& Herstatt, P.C., 1999. Approaches to the " Fuzzy Front End " of Innovation. , (2). 


\title{
APPENDIX 1
}

\section{MATE GROUP REPORT}

\author{
BY
}

\section{ISH JIMALE, LIAM HARKER, IAN WALSH, OLIVER TOWNEND}

\author{
Submitted to Victoria University of Wellington \\ In partial fulfilment of the requirement for the degree of \\ Masters of Advanced Technology Enterprise
}

Victoria University of Wellington

2014 


\section{Contents}

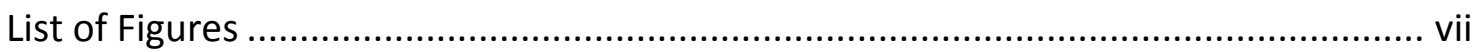

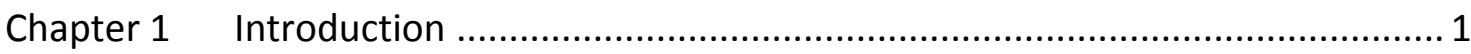

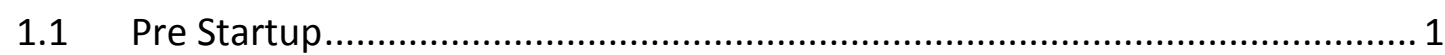

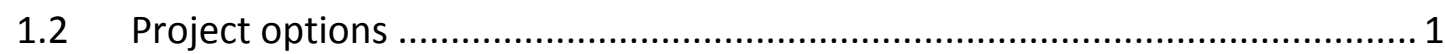

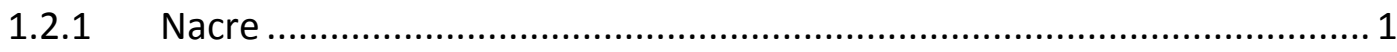

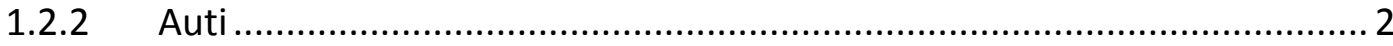

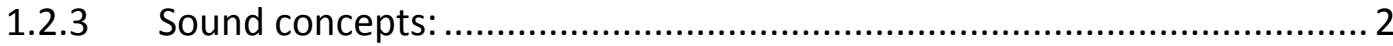

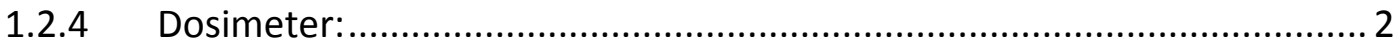

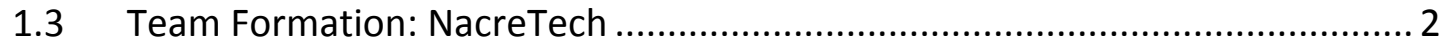

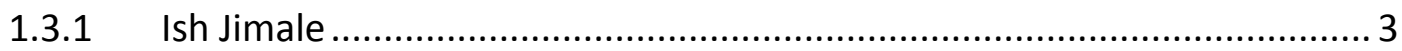

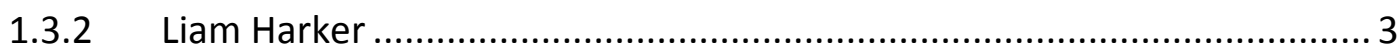

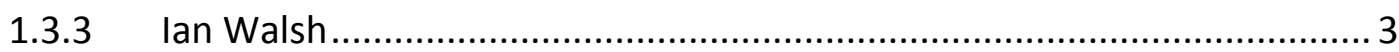

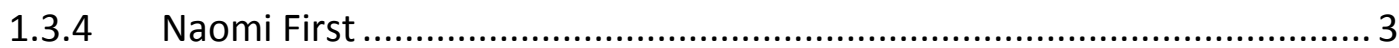

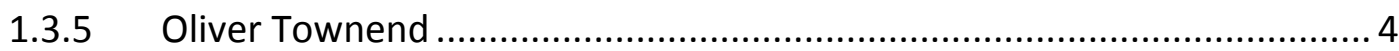

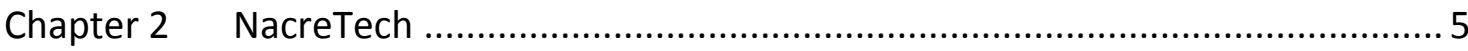

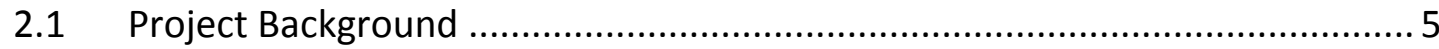

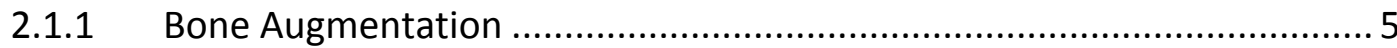

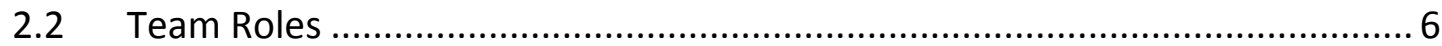

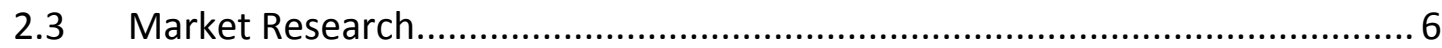

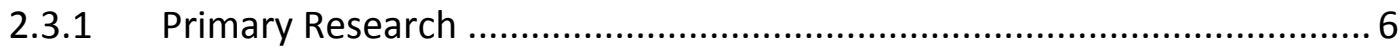

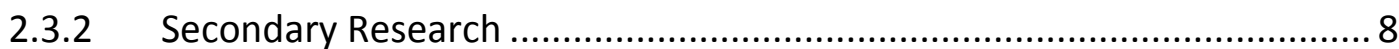

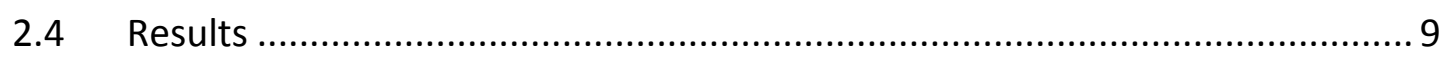

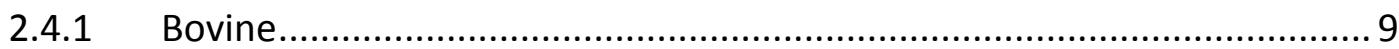




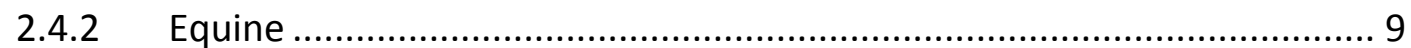

2.4.3 Canine and Feline

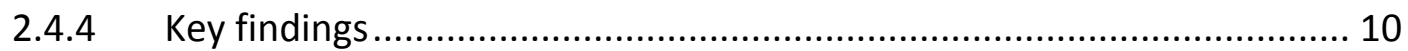

2.5 Pivot from Veterinary Dentistry to Veterinary Orthopaedics ....................... 11

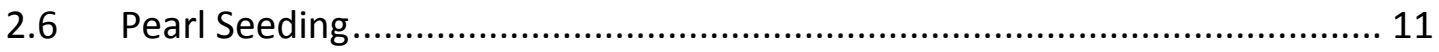

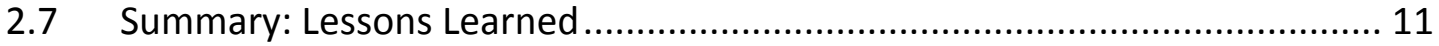

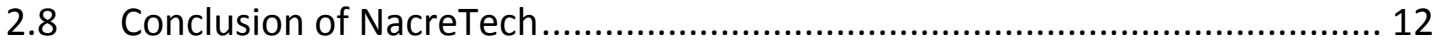

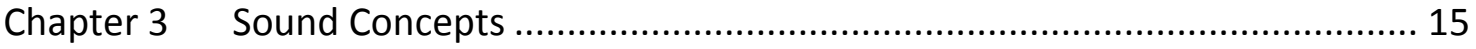

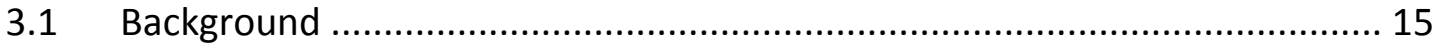

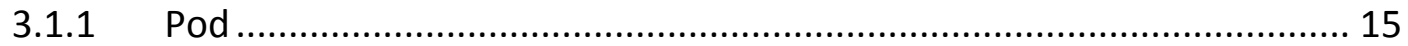

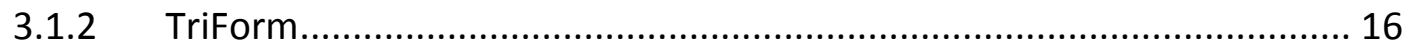

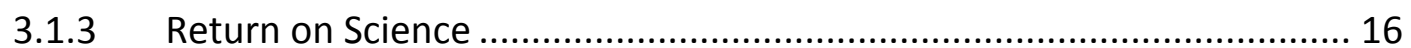

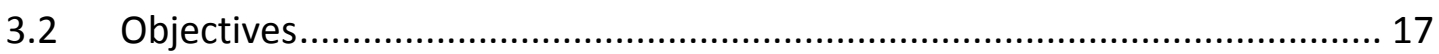

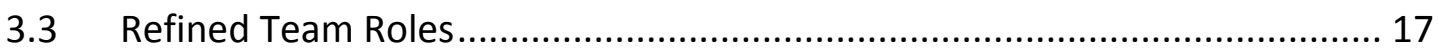

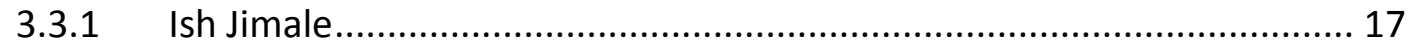

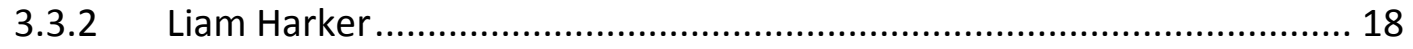

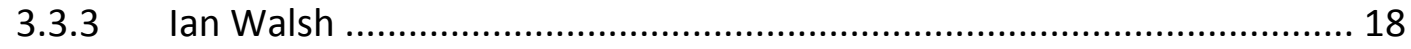

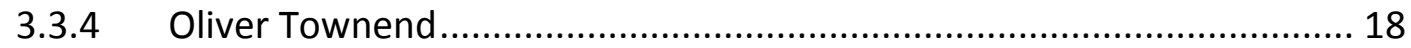

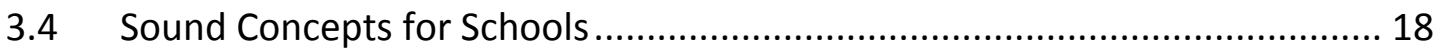

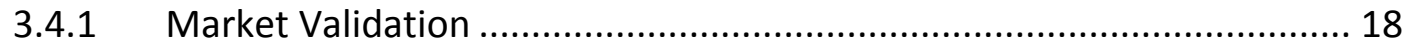

3.4.2 Summary of the School Market ............................................................ 19

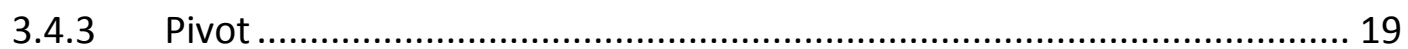

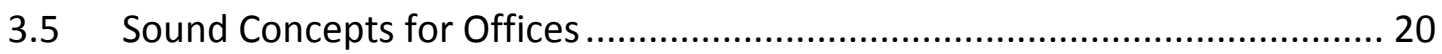

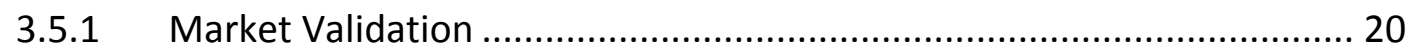

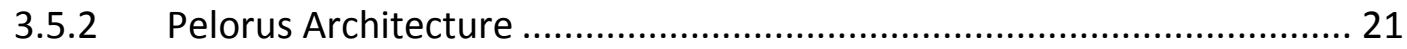

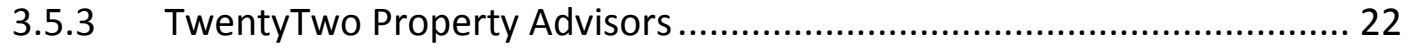


3.5.4 Summary of the office market …..................................................... 23

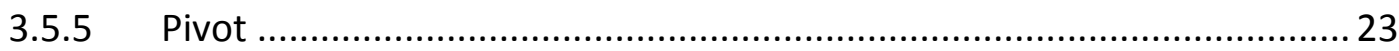

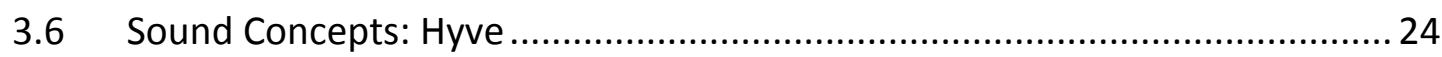

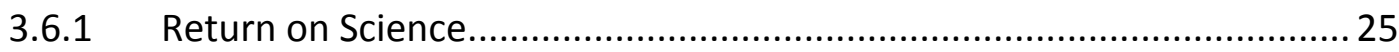

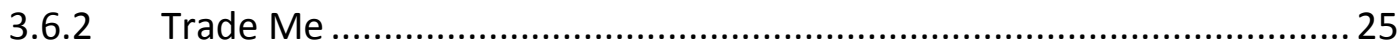

3.7 Supply Chain and Manufacturing Investigation ............................................. 26

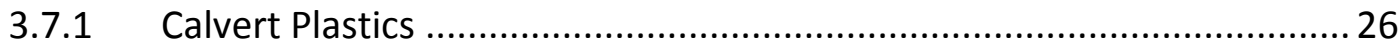

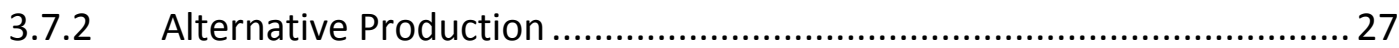

3.7.3 Anderson Design Meeting ............................................................... 28

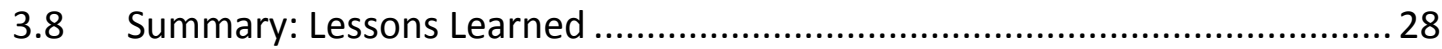

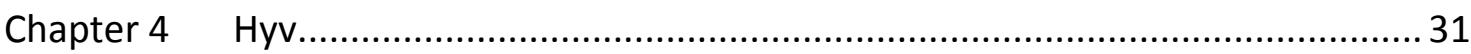

4.1 Targeted market research: Open plan offices …........................................ 31

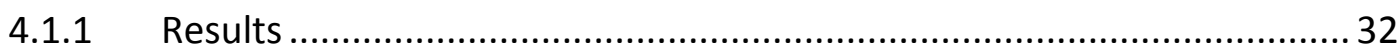

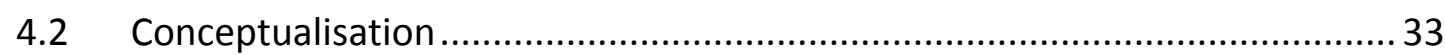

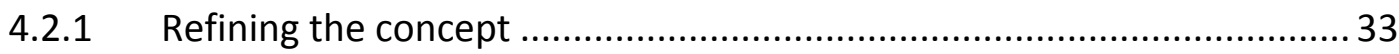

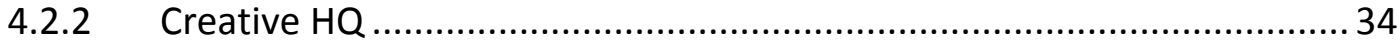

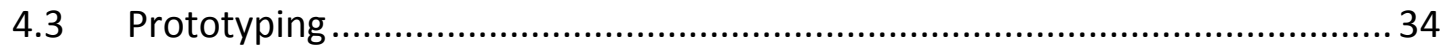

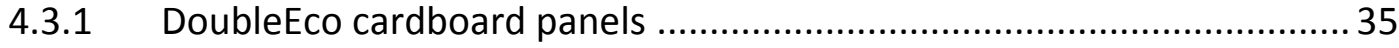

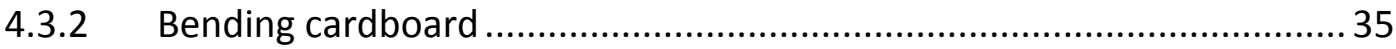

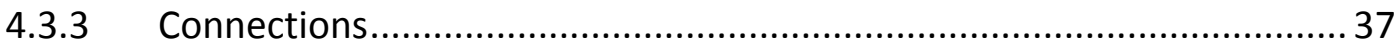

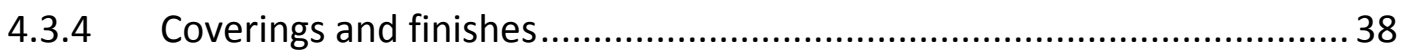

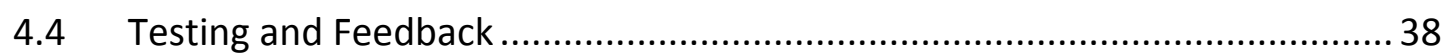

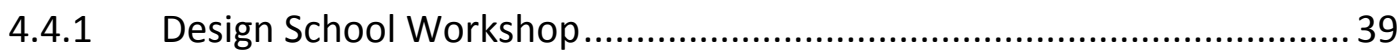

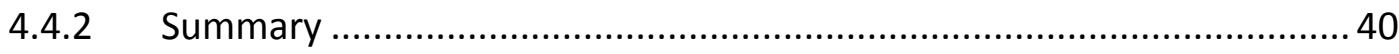

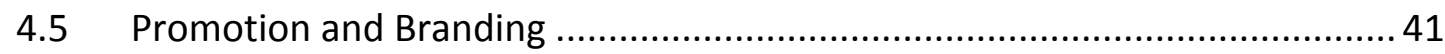

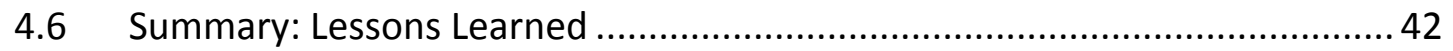


Chapter 5 Hyv2.0

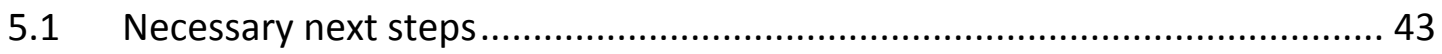

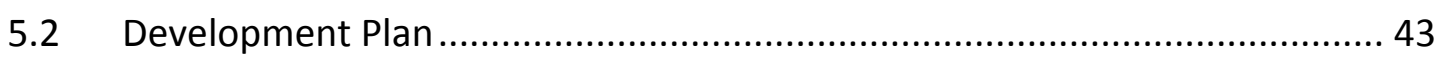

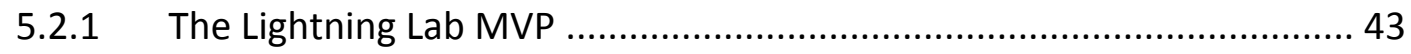

5.2.2 Tertiary Education Commission ........................................................... 44

5.3 Manufacture / Licensing potential ............................................................ 44

5.3.1 Formway Design Connection ......................................................... 45

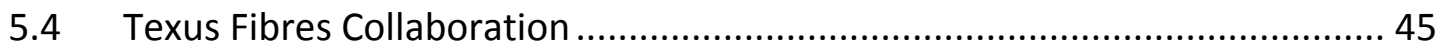

5.4.1 Tech Jumpstart Summer Project....................................................... 45

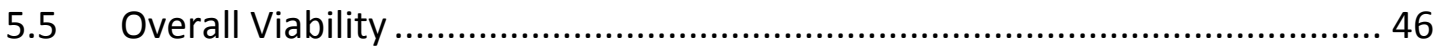

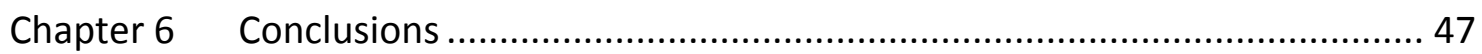

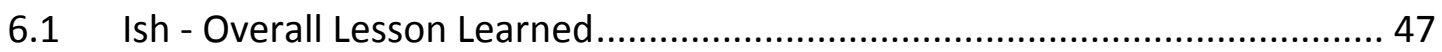

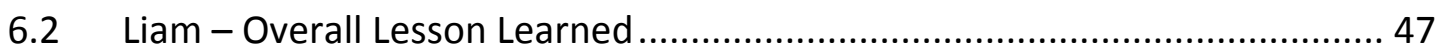

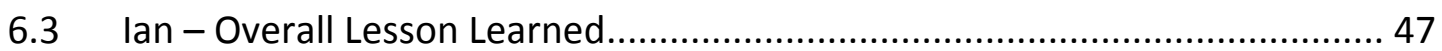

6.4 Oliver - Overall Lesson Learned ............................................................. 48

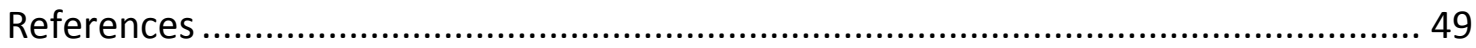





\section{List of Figures}

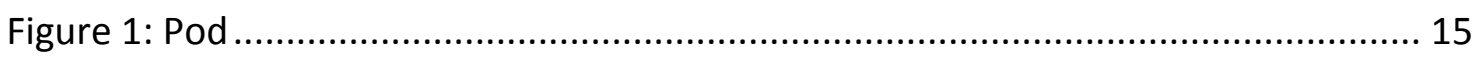

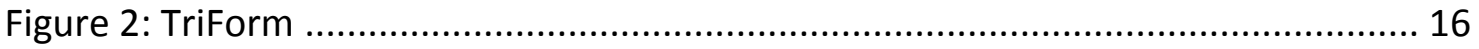

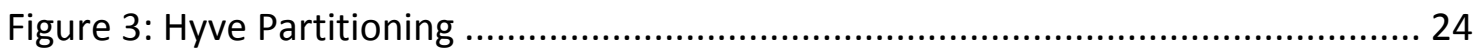

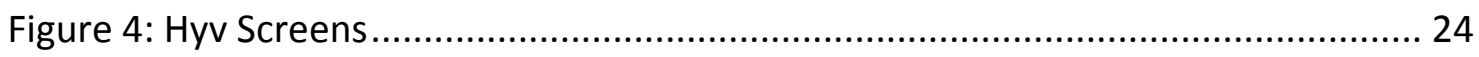

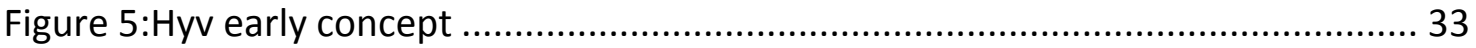

Figure 6: Bending cardboard and the finished panel .............................................. 36

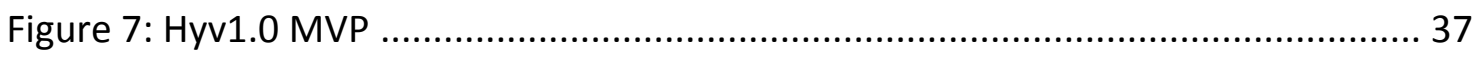

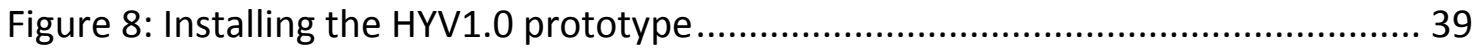

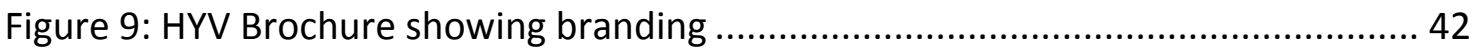





\section{Chapter 1 Introduction}

The purpose of this document is to provide background information to support the individual Masters of Advanced Technology Enterprise (MATE) theses of Ish Jimale, Liam Harker, lan Walsh and Oliver Townend (referred to as "the team" and later "Hyv"). It is a chronological record of the team's work in 2013 on the NacreTech, Sound Concepts and Hyv projects and summarizes the key lessons learnt in order to provide context to the individual submissions. Team members contributed to different chapters based on their particular interest.

\subsection{Pre Startup}

The 2013 Masters of Advanced Technology Enterprise programme brought together graduate students from a broad range of disciplines with the goal of experiential learning through the development of commercial entities with roots in ongoing VUW research. The initial four week ATEN501 programme exposed the students to experts from both academia and business, and theoretical models, in particular the Lean Startup (Ries 2011) and Osterwalder and Pigneur's Business model Canvas (2010).

\subsection{Project options}

Following this introductory stage, the MATE participants were tasked with assessing four potential projects and forming teams to begin commercialisation. Research projects that have shown latent potential for commercialisation were pitched by "project champions", typically university academics leading ongoing research projects, who presented background information as well as an initial strategy for commercialisation.

\subsubsection{Nacre}

Professor Kate McGrath, School of Chemical and Physical Sciences, VUW

Professor McGrath's research has resulted in a patented method for the production of synthetic nacre ("mother of pearl"). This biocompatible material has promising applications in the biomedical field as an alternative to current synthetic bone grafting 
materials. Use as a void filling material in veterinary dentistry was proposed as a first market entry point from which to ultimately develop human orthopaedic applications. (McGrath, 2013)

\subsubsection{Auti}

Helen Andreae, VUW School of Design

Auti is a robotic toy designed to respond to and reinforce positive behaviours in children with autism. Auti was pitched to MATE as a working prototype that simulated the responsive functions of the device through remote control. Further research into the effectiveness of this type of treatment was being undertaken by the Helen Andreae as part of an unrelated masters program. (Andreae, 2013)

\subsubsection{Sound concepts:}

Natasha Perkins, Senior Lecturer, School of Architecture, VUW

Sound Concepts aims to develop and test forms that will help reduce reverberation times in interior environments. The commercialisation proposal centred on testing the viability of two existing prototypes: Pod, a freestanding breakout space for primary school classrooms, and TriForm, a hanging acoustic baffle system. Sound Concepts was further developed than the other potential projects and the prototypes had already undergone performance testing in school environments. (Perkins, 2013)

\subsubsection{Dosimeter:}

Dr. Grant Williams, Professorial Research Fellow, School of Chemical and Physical Sciences, VUW

Dosimeters are used to monitor and detect radiation doses and dose rates. The technology presented to the team focused on a novel method of detection and measurement using optically stimulated luminescence. The project champion had built a prototype and was interested in connecting with customers to test the effectiveness of the device in a real-world application. (Williams, 2013)

\subsection{Team Formation: NacreTech}


Having assessed the potential of the projects, with consideration given to the students' applicable skillsets, Jimale, Harker, Walsh, First and Townend formed a team around a common interest in the Nacre and Dosimeter projects. Professor McGrath's Nacre research (under the team moniker NacreTech) was ultimately chosen due to its clear development path and potential for wide-ranging commercial application.

\subsubsection{Ish Jimale}

Ish has a background in both business and science, having graduated with double degree in biotechnology, management and international business from Victoria University. He has been working for the Ministry for Primary Industries in an information management role.

Ish's attention focused on the customer development process, including primary market research and building relationships with potential customers.

\subsubsection{Liam Harker}

Liam has a background in science with a strong focus on biotechnology. In 2012 he completed a postgraduate diploma in bioscience enterprise at Auckland University graduating with merit. His previous experience in early stage technology validation has helped him develop skills in intellectual property and market validation and market research.

Liam's MATE focus has been project management and market research.

\subsubsection{Ian Walsh}

lan has a business background with a focus on communications and customer relations. Ian is a customer support representative and strategy intern at Trade Me Ltd as well as being involved in the start-up community in Wellington, including Start-up Weekend and the Lightning Lab, New Zealand's first digital accelerator. He is particularly interested in customer development, primary market research, as well as marketing activities including brand development.

\subsubsection{Naomi First}


Introduction

Naomi has a background in business and consulting, specifically strategy, planning and organizational design work for public sector clients, as well as experience in management, marketing and business development

\subsubsection{Oliver Townend}

Oliver brings experience in industrial design, construction and small business operation. Following his design degree at Massey University Oliver moved into residential building to gain detailed insight into a vital industry, with the intent to apply his design skills at a later stage. In the MATE programme Oliver's focus is project management and product development. 


\section{Chapter 2 NacreTech}

\subsection{Project Background}

The first commercial application proposed for synthetic nacre is an injectable dental gel for veterinary use, suitable for filling the void created by tooth extraction. Finely ground nacre powder would be loaded into a biocompatible gelling agent with appropriate setting characteristics to create an integrated gel that would harden rapidly in oral applications. The hypothesis is that the nacre gel will protect the extraction site, thereby preventing infection and reducing healing time. Over time the gel will be resorbed and the osteoconductive properties of nacre will allow the growth of new bone and maintain structural integrity of the jaw.

\subsubsection{Bone Augmentation}

Filling the void left by tooth extraction is an example of the use of bone augmentation (commonly referred to as bone grafting). In humans, this procedure is relatively common in order to repair the jaw bone and provide support for prosthetics (false teeth). Bone augmentation procedures are relatively common in both human and veterinary orthopaedic surgery, with uses ranging from dental implants to joint fusions. The majority of these procedures use grafting material taken from a healthy site within the patient (autograft), commonly the iliac crest. This requires additional invasive surgery and increases patient healing times. Another option is to use material from a donor of the same species (allograft) which is heavily processed to remove all organic material and prevent rejection.

A bone graft substitute can augment or even replace the need for an autograft, reducing the negative effects on the patient. Synthetic substitutes have been on the market for approximately twenty years, however to date no synthetic material has achieved all of the attributes of an autograft.

Ideally, a bone graft substitute will achieve:

- Biocompatability - the ability to be in contact with living tissue without an adverse effect 


\section{NacreTech}

- Bioresorption - the material will break down in the body and not require removal

- Osteoconduction - the material acts as a scaffold around which new bone can form

- Osteoinduction - the material actively stimulates the growth of new bone tissue

- A similar physical structure to bone

While most current substitutes achieve osteoconductivity, very few achieve osteoinductivity. It is this quality that synthetic nacre must strive for.

The market for bone grafting materials is large at $\$ 1.9$ billion and is forecast to continue growing for the next 25 years in line with ageing populations. Performance is valued more highly than cost in bone grafting materials, particularly in the human market where the material itself represents only a small percentage of the overall cost of procedure.

\subsection{Team Roles}

At this early point the team had yet to split into specialised roles and members were focussed on a sole task: the validation of the potential of synthetic nacre based products in veterinary dentistry.

\subsection{Market Research}

This validation required a combination of primary and secondary research. Using Lean Startup methodology the team set about gaining an understanding of the veterinary dental market.

\subsubsection{Primary Research}

Following Steve Blank's "get out of the building" technique (2007), the team sought direct interaction with the proposed market. Through conversations with specialist veterinarians we set about to establish the "pain" or level of need for synthetic fillers in veterinary dentistry.

\section{WSAVA Conference}


On Friday 8 March 2013 Oliver Townend attended the WSAVA (World Small Animal Veterinary Association) Annual Congress in Auckland, specifically to gain an insight into the global veterinary industry and make contact with specialists in veterinary dentistry and orthopaedics.

Generally veterinarians, both generalists and specialists, understood the NacreTech concept. It quickly became apparent that while veterinary dentistry is not a large market, there is strong interest in effective bone augmentation products for use in orthopaedic surgery. At present bone augmentation in animals is not common since current products are ineffective and provide no measurable benefit over the lifespan of the animal.

Key Points:

- Not one of these specialists immediately identified major flaws in what we were proposing, although the introduction to the technology was brief, and based on some early predictions.

- While New Zealand veterinarians tend to be generalists, internationally animal dentistry is a growing specialisation.

- There is growing recognition that dental health has a significant effect on overall health, and that while animals may not display obvious symptoms serious issues may be developing.

- A nacre based bone augmentation product MUST have high osteoconductivity and MUST be absorbed by native bone cells fairly quickly in order to provide a significant benefit over existing products. It cannot be an inert filler.

- Our product would need to be simple to use and inexpensive, allowing us to market it as having significant benefits for limited extra effort. This will enable the product to gain traction in a market that is currently happy without it.

\section{Massey University}

On the ninth of April 2013 the team travelled to Palmerston North to meet with veterinarians at Massey University. We were able to speak with two specialists with experience in bone augmentation: 
- Dr Andrew Worth: Senior Lecturer in Small Animal Surgery (Orthopaedics)

- Dr Angus Fechney: Companion Animal Veterinarian (Dentistry)

Both expressed concerns over the lack of need for void fillers in veterinary dentistry, as they very rarely use these types of products. Generally if they are forced to remove a tooth from an animal it will heal naturally without the use of any additional products.

Andrew and Angus shared insights into the current use of bone graft substitutes, a market which they felt was saturated by products that did not deliver on their promised performance. Most of the industry uses autografts (tissue from the patient itself) or allografts (tissue from a donor of the same species) which have significant advantages over synthetic products - specifically the osteoinductive properties of natural bone which current synthetics cannot deliver.

\section{Estendart}

While in Palmerston North we took the opportunity to meet with $\mathrm{Dr}$ Alan Alexander from Estendart, a company operating within the Massey University Research Park which specialises in animal trials for development of medical products. The purpose of this meeting was to gain an understanding of the in-vivo (live animal) process, particularly to inform the in-vitro (laboratory) tests required initially. This process would ultimately test the safety of synthetic nacre as a bone grafting substitute.

The result of the meeting was a focus on in-vitro safety trials for synthetic nacre to prove that the material was non-toxic to living cells. Only after achieving successful results could we begin to look at setting up in-vivo tests in animals.

\section{Phone interviews:}

In February and March 2013, the team contacted eleven veterinary professionals within New Zealand including five specialist veterinary dentists.

\subsubsection{Secondary Research}

Most of the quantitative information gathered concerning market size, competitive products and market trends came from secondary research via industry reports and online databases, which provided an insight into the current state of the veterinary 
dentistry industry. The team was quickly able to determine that multiple competitors existed and was able to compare their products with nacre. It was established that existing void fillers belonged to a larger market of products called "bone graft substitutes" and had been relabelled or modified to be used in veterinary dentistry rather than developed specifically for this application.

\subsection{Results}

\subsubsection{Bovine}

Our research determined that this is not a viable market as dental health is not an issue in cows. Chewing cud effectively cleans the teeth and gums and prevents tooth decay. Cow's teeth continue to grow and to be ground down throughout the life of the animal. Tooth extraction is rare and when it does occur the site heals without issue.

\subsubsection{Equine}

Horses have a very different dental anatomy to humans. As with cows, the teeth continue to grow and are constantly ground down by mastication. When a tooth is removed the surrounding teeth will move to fill the space created and the forces involved are tremendous. According to Elizabeth Thompson from Blue Mist Equine Dentistry, if a material was implanted into the jaw it would need to have the strength of titanium to withstand the pressure of the other teeth. Infection post extraction is not a problem. Horses tend to easily react strongly to foreign bodies (for example calcium carbonate) in the mouth, and their introduction may lead to additional complications.

\subsubsection{Canine and Feline}

Dogs and cats have dental anatomies much closer to those of humans. Companion animal dentistry is a relatively new but growing field as pet owners become more aware of, and are prepared to spend more on their animal's oral health. There have been marketing campaigns from both veterinarians and producers of dental health products to promote dental health awareness amongst pet owners.

In light of this information, the companion animal market was selected as the most suitable application for nacre as a dental filler. 
Further exploration into this market revealed that while dental fillers were indeed used in the companion animal market, the number of veterinary dentists who use dental fillers following tooth extractions is extremely small. In fact, in most cases the resulting cavity was left to heal by itself without complication. Of the eleven veterinary professionals we spoke with, only two used dental fillers and they did so only when complications such as severe infection or trauma to the jaw bone were involved.

\subsubsection{Key findings}

Our research into the veterinary dental market has indicated that

- Dentistry in livestock (equine and bovine) is a small market. On those occasions where tooth extractions do occur there is no requirement for a filler or bone augmentation product.

- Dentistry for companion animals internationally is a developing market that is expected to continue to grow. However generalist veterinarians, who perform the majority of dental work on companion pets, rarely use a socket filler or bone grafting material following tooth extraction as sites usually heal well without the use of any specialised materials.

- The use of dental bone augmenting materials tends to be restricted to 'premium' veterinary practices that specialise in dentistry, of which there are few. Even in these practices void filling is often considered unnecessary as the introduction of a foreign body may exacerbate the condition.

- There is an abundance of products on the market that can be used for void filling.

- There are some oral conditions in animals where bone grafting material are more commonly used by the surgeons e.g. fracture repair and oral-nasal fistula. In these cases an integrated gel is likely to hinder the repair process.

- An ideal dental bone grafting material requires the following characteristics:

- An osteoconductive matrix or scaffolding to support bone growth

- Osteoinductive factors that stimulate and recruit host mesenchymal cells 
- Osteogenic cells that survive transplantation with the potential to differentiate and stimulate the various phases of bone formation

- Structural integrity to ensure the graft won't collapse or be displaced

\subsection{Pivot from Veterinary Dentistry to Veterinary Orthopaedics}

In response to these findings, the team decided that veterinary dentistry is not a sufficiently large market for continued focus. Veterinary orthopaedic surgery offered a much better market entry point through the use of synthetic nacre as a bone graft substitute.

\subsection{Pearl Seeding}

As an alternative to medical applications, the team briefly explored an application of nacre to seed pearls in oysters. Currently, pearls are artificially created en masse by placing a "seed" inside of the shell of an oyster. The oyster then coats the seed in nacre to create a pearl over a period of time. Generally these seeds are pieces of mussel shell that are shaped into spheres. Larger implants are harder to come by as they require the use of mature shellfish with thick shells. These are not abundant given current practice of harvesting shellfish while they are still comparatively young. It was hypothesised that synthetic nacre could be used to create these larger implants.

Exploration of the market revealed that the pearl industry has recently undergone a dramatic shift that has reduced the overall production of traditional oyster grown pearls. Chinese pearl farms have developed a method of growing multiple pearls within fresh water mussels, greatly reducing the cost of producing high grade pearls and dramatically affecting the demand for seed material.

In light of this information it was clear that the solution offered by nacre was in the process of being phased out and would unlikely be needed in five years. The team made the decision to suspend research into pearl seeding at this point.

\subsection{Summary: Lessons Learned}

- Exploring customer need can often yield new information, leading to changes in product requirements and specifications. Be prepared to change. 


\section{NacreTech}

- Effective communication between all those involved in a project like this is extremely important. Everyone should be involved and on the same page.

\subsection{Conclusion of NacreTech}

The following is an excerpt from the NacreTech final report, presented to Professor Kate McGrath on the 6th of May, 2013.

There is resounding evidence that current methods of treatment following a tooth extraction within the veterinary dental market are deemed acceptable. If and when fillers are required there are adequate products already in the market with features that include biocompatibility and osteoconductivity.

The wider field of synthetic bone grafting does appear to have some potential. There is strong evidence of a yet unmet need for a synthetic product that has all of the qualities of an autograft. There is a significant international research and development effort focused on developing this 'gold standard' product.

The ability of naturally occurring nacre to support the regeneration of bone has been demonstrated in published research trials on animals. If it can be shown that these properties can translate to synthetic nacre this material could be a promising candidate for use in bone grafts. This has applications for surgery on both humans and animals.

To enter the bone graft market, synthetic nacre would need to prove that it matched the properties of leading synthetic bone grafting alternatives. Once these properties have been verified, product development would be required to ensure the development of a viable product in forms that would meet market need, while being cost effective. Even with the right product, entry into this very crowded market would not be easy without the right partners and relationships in place.

Based on our understanding of the materials research to date, NacreTech do not believe that the testing necessary to prove synthetic nacre's properties could be completed within the timeframe of the 2013 MATE programme. The 
NacreTech team has therefore concluded that product development at this stage is premature.

The NacreTech team recommends that work is not continued on the specific application of synthetic nacre as gel-based dental filler due to the low use of comparable products. Also, that testing is undertaken to assess the following properties of synthetic nacre before product development commences:

- biocompatibility

- level and speed of bioresorbtion

- level of osteoconductivity

- level of osteoinductivity

- structural integrity and strength.

Once testing has confirmed that synthetic nacre has the required properties, either Viclink or a future MATE team pursues product development and commercialisation.

Based on these conclusions the NacreTech team ceased work on the project, presented our report to the project champion and handed responsibility back to the researchers. Synthetic nacre shows strong promise for application to veterinary orthopaedics if it can be shown to meet the needs of the bone augmentation market. It is our hope that the technology will be picked up at a later stage for continued development.

At the completion of the NacreTech project, Naomi First made the decision to leave the MATE course for personal reasons, reducing the team to four. 



\section{Chapter 3 Sound Concepts}

\subsection{Background}

School of Architecture Senior Lecturer Natasha Perkins has developed a series of products designed to reduce reverberation times in interior environments.

Technical research was undertaken during 2010-12 to develop and produce prototypes of a freestanding children's breakout space (POD) and an acoustic baffle system (TriForm) for pilot installation and testing in primary schools and community halls.

Companies that would use the products include architects and specifiers for commercial fit-out, schools, and council halls to upgrade acoustic performance of interior environments - this could be on a national and international level. Previous offshore market research with architects has shown a need for 3D acoustic forms within commercial and learning spaces.

\subsubsection{Pod}

Pod was designed as a freestanding acoustic product for use in primary schools. It is made up of hexagonal panels that form a structure for children to occupy and play in. The panels themselves are formed from a polyester acoustic material produced by Autex Industries.

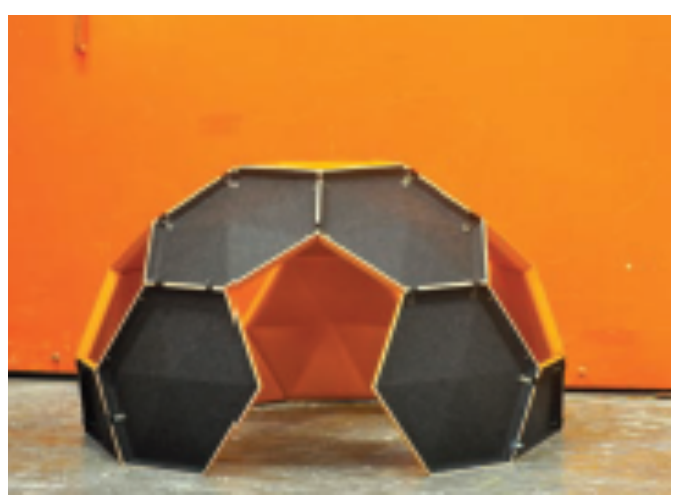

FIGURE 1: POD 


\section{Sound Concepts}

The product was designed to act as a passive absorber of sound within a classroom environment while providing a calming, quiet space to aid children, in particular those with central auditory processing disorder or other hearing impairments.

\subsubsection{TriForm}

TriForm is a series of individual quadratic components, joined together to form a geometric acoustic baffle. A system of these baffles can be incorporated into the ceiling space of classrooms and public spaces.

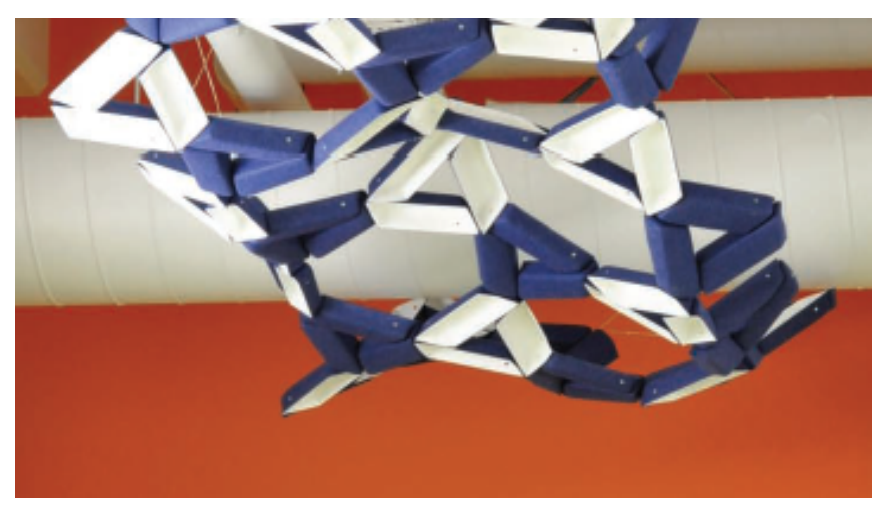

FIGURE 2: TRIFORM

With its suspension flexibility, the intention of Triform was to be used in large quantities to absorb a range of sound frequencies and reduce reverberation in interior spaces.

\subsubsection{Return on Science}

Prior to the MATE team's involvement, start-up consultant Michael Elwood-Smith was contracted by Viclink to carry out a market scan on Sound Concepts to identify its commercial potential. He presented his findings to the Return on Science investment committee, a national research commercialisation programme that works with technology incubators to bring new research to market from universities, research institutions and private companies. His findings are summarised below:

- A growing global market is identified for products that improve room acoustics and are aesthetically pleasing. 
- The combination of acoustic performance, aesthetic design and eco-friendly products is of interest to potential customers and users, and fits with market trends.

- There is potential added-value for a software product/service to support the application of products within rooms, which is likely to be used by architects.

- The best and first product/market fit and therefore the scalable business model is not yet clear.

- Commercialising this work would best suit a start-up company where the first objective is to discover the true market potential, product fit and scalable business model.

- Both current forms appear to have potential market fit. However, further work is required to define the initial target markets and the appropriate product to suit that market.

\subsection{Objectives}

The MATE team was expected to continue this assessment of the viability of Pod and Triform in the school market. We were also given the opportunity to explore other markets to see if these products could be of benefit to a paying customer.

As a team we sought to broaden our exploration of customer needs rather than trying to fit a product into an existing market. We sought to better understand whether there is a need for acoustic products in various markets, how much of a pain point exists, find out how these prospective customers were currently addressing the issue and how much they were willing to pay to solve it. This broader approach saw the team undertake validation activities across multiple markets, as well as speaking with architects, designers and acoustic consultants.

\subsection{Refined Team Roles}

\subsubsection{Ish Jimale}

Ish concentrated on validating the market for the Sound Concepts products. The main objective was to collect market data that will be used to drive decision making processes. 


\section{Sound Concepts}

\subsubsection{Liam Harker}

Liam tested assumptions about the products appeal and performance in the market by engaging customers and industry experts in phone and face-to-face interviews.

\subsection{3 lan Walsh}

Ian focused on market validation efforts. He was responsible for contacting school principals and property managers around the country.

\subsubsection{Oliver Townend}

Oliver investigated the supply chain and manufacturing processes of the current products and explored potential alternatives.

\subsection{Sound Concepts for Schools}

The primary goal of this stage was to assess the commercial potential of Pod and TriForm's use in school classrooms, as proposed by the research team.

\subsubsection{Market Validation}

As an initial scan of the educational market, we canvassed school property managers across the country, in primary, immediate, special needs and secondary schools across the state and private spectrum. We made phone calls to managers asking them to express their problem, rather than trying to sell them our solution. We asked the following questions.

- Do you take acoustic performance and noise control into consideration when fitting out the interior of a classroom?

- Have teachers expressed concern about the level of noise in classrooms?

- What is your main motivation for improving acoustics in a classroom?

- How do you currently address this issue?

- What types of products do you use?

These questions allowed the customer to elaborate on needs, problems and issues that they deal with daily, and gave structure to the conversation. After interviewing twenty seven decision makers in schools, patterns began to emerge. Here is a sample of the feedback we received. 
- Acoustics are taken into consideration when fitting out classrooms, though this is usually left up to the architect.

- Some teachers have expressed concern over interior acoustics and excessive noise but these issues are not considered a major problem on the whole.

- Current solutions include soft furnishings, acoustic ceiling tiles, carpet, pin boards.

- One respondent had recently installed Autex acoustic wall coverings, stating that it was "very expensive" but the "best money ever spent!"

- Amplification (speakers and audio equipment) are used with varying success.

- For many schools, interior acoustics are a "nice to have" but with limited budgets priority must be given to seismic strengthening and other costs.

- There is growing awareness of the needs of children with hearing problems.

- Noise generally only given serious consideration in "special use" spaces: workshops, music rooms etc.

\subsubsection{Summary of the School Market}

- The acoustic environment of a classroom is a concern and a need that property managers consider when refurbishing.

- Private schools (primary and secondary) more often have the funds to improve the acoustic environments of their classrooms. However, this budget is usually spent on existing solutions such as acoustic ceiling tiles and wall linings.

- State Schools (primary and secondary) do not have large enough budgets to invest in acoustic products as they have other concerns.

- Although a need has been identified, there are dominant competitors in this space. In particular, Autex in the New Zealand market.

\subsubsection{Pivot}

Our research determined that the market for specialised acoustic products in schools is small and often restricted by budget constraints. The team began exploring alternative markets for Sound Concepts designs, identifying commercial office spaces as having significant potential. An increasing number of organisations are switching from traditional offices to more open plan, decentralised work environments. This can 
be to encourage collaboration, promote good work habits and to save costs. Acoustics in this environment are consistently ranked in the top three "most important considerations" by architects when fitting out new office spaces. Many organisations introducing open plan offices have substantially larger budgets for acoustic issues than schools. In light of the team's preliminary findings, we decided to focus on open plan offices as a market entry point for Sound Concepts.

\subsection{Sound Concepts for Offices}

The team began exploring this direction with the goal of identifying the key requirements of office spaces, in order to inform the development of further Sound Concepts designs.

\subsubsection{Market Validation}

Preliminary investigations into the commercial office market identified that workers in open plan offices consider noise to be a substantial problem. We spoke to office managers on the phone to ascertain the importance of reducing sound reverberation and to learn how they were currently addressing that issue. We discovered that office managers do actively consider the acoustic environment in the office and use a range of acoustic products to manage it.

Key findings:

- Significant acoustic consideration is given to meeting rooms, quiet spaces and video conference rooms, motivated by the need for client confidentiality and general staff productivity

- Acoustics accounts for roughly $5 \%$ of fit-out costs

- Current solutions include soft furnishings, perforated wooden wall panels, inwall insulation, ceiling tiles, acoustic blankets.

- Acoustic engineers are sometimes contracted at significant cost to assess the requirements of spaces

- "It all comes down to one person, the marketing guy next to the accounts guy." Nigel Lloyd, Acoustic Consultant, Acousafe Consulting \& Engineering Ltd 
The following are case studies which provided key information on the feasibility of Sound Concepts in office spaces.

\subsubsection{Pelorus Architecture}

We interviewed Don Taylor on August 30 2013. Don is a 'friendly contact' introduced to us by Professor Sally Davenport, one of the MATE supervisors. Up to this point, most of the interviews with commercial architects were conducted by telephone. We now had an opportunity to speak face to face, which we found is the best way to get essential information in order to steer the team in a particular direction.

One of the key insights from this meeting was the confirmation that there is a need for customisable solutions that can create semi-private spaces within offices. Fuelled by the growing number of organisations switching to open plan offices, architects face the challenge of creating a range of work environments within a single space. In particular Don articulated the challenge he faces when trying to create semi-private spaces where employees can take phone calls, collaborate and have discussions without disrupting colleagues.

Don's current arsenal for the creation of "breakout spaces" consists of either constructing bespoke solutions or specifying soft furniture. Depending on an organisation's budget, bespoke jobs can range from low cost meeting spaces constructed from readily available materials, all the way to "showpiece" jobs that can cost in excess of $\$ 30,000.00$. The approach is limited by several factors:

- The lead time to get them built

- Requirements for sprinklers, lighting and air flow

- Difficulties in making changes to the structures once installed

- Added cost of restoring the premises to its original state at the end of the lease.

When quizzed about an ideal solution, Don spoke about the need for a product that incorporates an element of standardisation, which he can then use with his design expertise to add a customised dimension. He envisioned an easily assembled frame to which he can apply various materials, resulting in customised partitions. The ability to 
use different materials was particularly appealing to him given the distinctive needs of different organisations. For example, organisations with limited budgets are more likely to cut costs by opting for simple, non-acoustic materials.

\subsubsection{TwentyTwo Property Advisors}

Over the course of the Sound Concepts project we spoke to several property advisors. These organisations often play a key role in all things "property". For instance, when an organisation is moving into new premises or renegotiating lease terms, contacting a property advisory firm is often the first step. Sitting on top of the property "food chain", these companies can negotiate lease terms and building modifications. Importantly for us, they have a wide range of industry contacts including with architects, designers, project managers and contractors. In essence they oversee the commercial office fit out process and bring together different parties as required.

Duncan Mitchell from Wellington company TwentyTwo Property Ltd is someone with whom the team built a close relationship with over the course of the Sound Concepts project. Duncan has shown real interest from the beginning of the project, partly because his firm conducts research into improving work environments. Duncan provided us with well-balanced feedback that took into account the various aspects his company must consider. In helping us validate the feedback from Pelorus Architecture and others, Duncan alerted us to the following key considerations:

- There is often a 'disconnect' between what architects perceive as an appropriate solution and the core requirements of the end users. This leads to too many custom solutions not being used as intended. Duncan recalls one incident where a firm invested substantial amount of money in a bespoke "creative space"; only for it to end up being used for people to eat lunch.

- He stressed that there is a need for a more customisable, reconfigurable way to meet changing business needs given the turbulent climate that most industries are currently experiencing. Further, any potential solution must be affordable.

- There are a few solutions already in the market, but most are very expensive and are thus not accessible to many organisations. 
- Furniture solutions such as high-backed couches have their limitations, particularly in the lack of customisation. The cost per unit (approx $\$ 7000$ ) is not outrageous but the average organisation would need 3-5 units, which quickly escalates the total investment.

- Don advised us that the best people to talk to are the end users and property managers.

- He offered to trial prototypes with some of his clients.

\subsubsection{Summary of the office market}

We had validated our assumption that commercial office environments require acoustic treatment, however we had not validated whether Sound Concepts products would satisfy the customers' requirements.

The findings above demonstrate the need for acoustic products in certain areas such as meeting rooms and waiting areas. As there is significant competition in the field of acoustic ceiling tiles, the team decided to focus on customisable, versatile products for creating meeting spaces at ground level in open plan offices.

It was at this point we explored the potential for an adaptation of the Sound Concepts prototypes, to see whether it could be used to produce a meeting room shell or "room within a room" with reduced sound reverberation. This product would also act as a visual barrier, adding to the aesthetics of the office. We refined the focus of our research to the use of "breakout" spaces or semi-private meeting areas, which allow office workers to get away from their desks to have informal meetings.

\subsubsection{Pivot}

We understood the greatest need was to develop meeting spaces or "rooms within a room", but that the acoustic capability of the product could not be the defining value of our proposition to customers.

Having focussed on 'design' and 'aesthetic appeal' during the market validation, we now shifted our focus to a 'design-led acoustic solution' rather than simply acoustics. This strengthened our core aim of providing an attractive, productive space that would have some noise dampening qualities. 


\section{Sound Concepts}

\subsection{Sound Concepts: Hyve}

Based loosely on the formed polyester structure of the Pod and TriForm concepts, and taking into account the market data we had gathered, we developed a series of designs to demonstrate a new concept: we sought to develop an aesthetically appealing breakout solution for office spaces; further, we sought to develop a product that was informed by customer feedback. We called this product Hyve, pronounced hive.

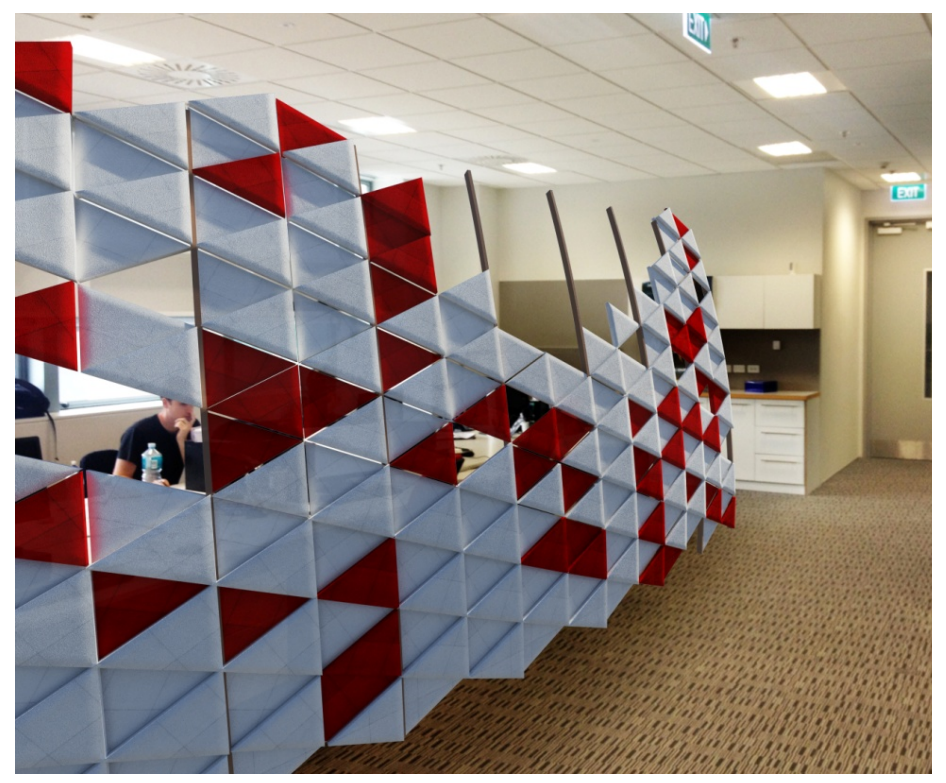

FIGURE 3: HYVE PARTITIONING

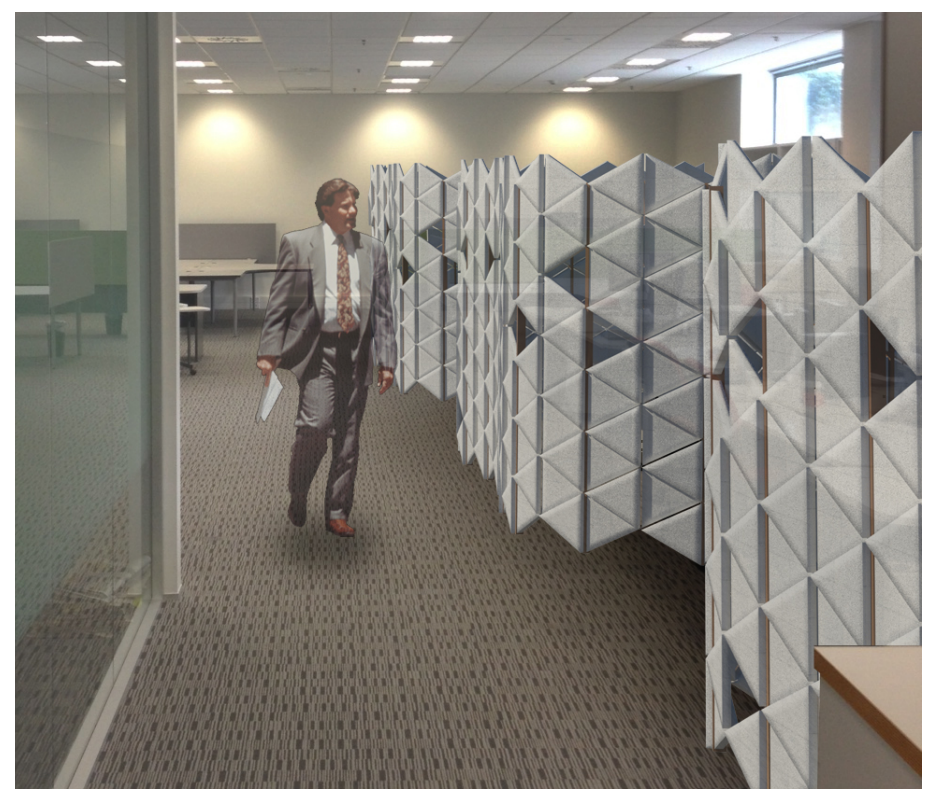

FIGURE 4: HYV SCREENS 


\subsubsection{Return on Science}

The team returned to the Return on Science investment committee on August the $15^{\text {th }}$ 2013, for guidance and potential funding through "Stage 1" of their commercialisation process. This would support further progress towards product development. We presented the following findings to support the case for developing Hyve.

- Office managers and workers are interested in 'pop up' meeting rooms or breakout spaces within leased offices and at conferences and tradeshows where people are looking for a sense of privacy (visual and aural) to conduct meetings in crowded, noisy spaces.

- It is believed that such spaces can be designed and built with the PET material forms and framework at a competitive price, with good margins, and could find a significant market.

- The core value in the work is in product design rather than acoustic performance

- The raw materials and manufacturing rely on third parties.

Upon review, the committee felt that there was too much completion in the office furniture market and that the project lacked adequate "scientific" involvement (an important factor of their assessment criteria). The committee was concerned that there was no unique selling point that would set this concept apart from more established commercial office furniture suppliers. The lack of proven acoustic gains also caused concern. As a result the Return on Science committee decided not to fund the continued development of the project.

\subsubsection{Trade $\mathrm{Me}$}

The team arranged to meet with Michael O'Donnell, Head of Operations at Trade Me, as they will be changing offices in 2014 and refurbishing three floors of office space. Michael arranged for all the parties involved in the new fit out to meet so that the team could ask them direct questions and gain insights into the refurbishment process. The main aim of the meeting was to understand:

- Who the key decision maker is within the group? 
- Who selects the interior products, including acoustic products?

The meeting brought together Herriot + Melhuish Architects, L.T. McGuinness Ltd (construction contractors) and Trade Me's office managers. During the meeting we gained specific feedback about our direction, our approach and what we would have to do in order to make our proposition valuable to them as customers. We also discovered that the key decision maker in this process was the Head of Operations. However, he is still influenced by the recommendations of the architects and interior designers.

With this information we were in a better position to target our market validation efforts on senior executives rather than office managers. We also learnt that understanding the needs and motivations of architects is vital as they are key influencers in the customers' purchasing decision.

\subsection{Supply Chain and Manufacturing Investigation}

The primary goal of this stage was to understand the process currently used to produce the Sound Concepts prototypes, and to determine whether this method is appropriate for large scale manufacturing.

\subsubsection{Calvert Plastics}

The Pod and TriForm prototypes have been manufactured by local company Calvert Plastics, specialists in thermoforming of plastic sheet. On May 30th 2013 we met with Darryl Pickering to learn about their manufacturing process. Calvert are a manufacturing company and are not experienced or interested in directly marketing their products. They currently produce a range of formed polyester wall panels made from Autex material that are sold back through Autex.

- Calvert are looking to find new distribution channels (other than Autex) for their products

- They're conscious of the fact that Autex could manufacture in-house if they wanted to.

- They encouraged us to look into international markets immediately 


\section{Production}

Sound Concepts designs are produced by heating and pressing (thermoforming) flat polyester sheet in a three-dimensional mould. The process is labour intensive and not currently set up for large volume production. If demand is high enough Calvert will purchase a new machine to dramatically improve the production times.

- Current machine setup can produce approx one unit every three minutes.

- New machinery would do exactly the same process but with higher level of automation and faster turnaround, potentially two at a time.

- New machinery built specifically for this process estimated to cost $\$ 75,000.00$

\section{Custom Fit outs}

In 2012 Calvert Plastics were contracted to produce custom panels for the ceiling of the Air New Zealand Koru lounge at Christchurch Airport. Rather than manufacturing in their Lower Hutt factory they built a mobile jig to form the panels on site which made transport much more efficient and prevent damage prior to installation.

- Air NZ Koru lounge was essentially a prototype for future custom fit outs.

- Custom fit out more profitable for Calvert as they can charge for design, prototyping, building jigs etc.

- Price obviously acceptable as Air NZ is in talks to do same with next Koru fit out.

- While these jobs are profitable, they are few and far between.

- They need a network of architects, especially from big firms such as Jasmax, to specify these fitouts.

\section{Furniture}

- "This stuff is good for furniture as long as you don't touch it" - Polyester acoustic material is hard to clean.

- White surfaces are not advised as they look dirty very fast.

- Calvert are maintaining a focus on wall and ceiling panels, rather than sculptural forms

\subsubsection{Alternative Production}


Initial investigation into production methods was unsuccessful in establishing a viable alternative to Autex material and thermoforming to produce Sound Concepts products. Sourcing the raw material directly from manufacturers in China was considered however this would require large scale production to be feasible and if this scale was achieved production of the components would likely be offshore.

\subsubsection{Anderson Design Meeting}

Representatives of the team met with lan Anderson of Anderson Design, specialists in the construction of custom fit outs for displays and exhibitions. lan recognised the trend of communal "breakout spaces" - in fact Anderson Design have produced custom spaces in the shape of giant rugby balls for the New Zealand Rugby Union. Companies use commission pieces such as these to create a brand-specific atmosphere. Acoustics are a consideration. Andersons have been in discussion with Autex Industries about use of their materials, though acoustics are only one of many factors.

lan believed a breakout space such as the Hyve office version could easily be manufactured "custom" but would be expensive and he didn't see any market for mass-produced units. At the likely price level businesses would rather have a unique product - something that no one else has.

\subsection{Summary: Lessons Learned}

In the process of investigating open plan offices we interviewed approximately sixty people including office workers, property managers, architects and manufacturers to learn about the issues they face and their requirements for a product that will address them.

- Many people are not satisfied with their current open plan work environment.

- The majority expressed interest in a system that creates semi-private spaces within open plan offices

- The ideal solution should be versatile, simple to setup and affordable.

- It should control noise and provide a sense of privacy.

- Architects have considerable influence on product specification. 
- The market for polyester-based acoustic sheet is dominated in New Zealand by Autex Industries.

- Aesthetics are important for some customers, but functionality is more important.

- Architects want better ways to improve acoustic performance of interior spaces.

- They are interested in a system that will improve their results without the need to hire acoustic consultants.

This feedback indicated an opportunity exists in open plan offices.

The Sound Concepts derived Hyve system could potentially address this opportunity, however:

- The concept was not considered sufficiently novel

- The level of functionality did not justify the predicted cost of production

- The aesthetics were polarising, indicating that it was best suited to custom installations rather than mass production

- Therefore, there was no product-market fit.

The team decided to set aside all existing prototypes and preconceived solutions and to build on the opportunity we had identified. 



\section{Chapter 4 Hyv}

The team (now under the moniker Hyv) had a substantial body of information and a network of contacts with an interest in improving open plan environments. This put us in an excellent position to develop a market-driven solution. This required a shift in mindset from "technology push" to "market pull". A market driven approach would differ from the technology push we had experienced through the NacreTech and early Sound Concepts projects in several ways:

- Any product or solution would be developed in response to market requirements gathered through our research

- These market requirements would be refined through feedback into a product specification

- Specification would be refined through an iterative product development process

\subsection{Targeted market research: Open plan offices}

The team began by constructing a survey designed to empirically confirm the need for semi-private meeting spaces within open plan offices and to clarify their key requirements. We sought to quantify the information we had gathered thus far by resurveying the contacts we had established during the phone survey process. We needed to determine the relative importance of the product requirements in order to distinguish between the "must have" and "nice to have" features. Further, we were keen to discover any requirements we might have missed during earlier interviews.

Based on our initial conversations, we now asked: "How important are the following attributes?"

- Simple to install, not requiring building consent, contractors or major construction.

- Lightweight (can be moved easily by one person)

- Reconfigurable for use in a variety of different spaces 
- No higher than $180 \mathrm{~cm}$ to avoid the need to move sprinklers or to get building consent.

- Freestanding without the need for additional supports such as bolts or ceiling suspension.

- Have acoustic properties that dampen noise

- Data/power options built into the structure of the product

- New Zealand made

- Environmentally friendly

- Cost effective

\subsubsection{Results}

Our contacts were asked to rank the importance of each product feature and how it would affect their purchasing decision on a scale of 1-10, with 10 being a feature of great importance or value. This provided an understanding of which requirements would influence the customer when making a decision. The market requirements determined for a meeting room product with acoustic benefits were, in order of importance:

1. Simple to install (not requiring building content, contractors or major construction)

2. Freestanding without the need for additional supports such as bolts or ceiling suspension

3. No higher than $180 \mathrm{~cm}$ to avoid the need to move sprinklers or get building consent

4. Data and power services built in

5. Acoustic properties to dampen noise

6. New Zealand made

7. Environmentally friendly

8. Lightweight (can be moved easily by one person)

9. Reconfigurable, for use in a variety of different spaces

10. Cost-effective 


\subsection{Conceptualisation}

The team began work on a "green field" design, created from scratch in direct response to the requirements and feedback from our market research.

A concept was created in digital format that sought to address the user's requirements while achieving appropriate cost effectiveness, manufacturability and aesthetic appeal.

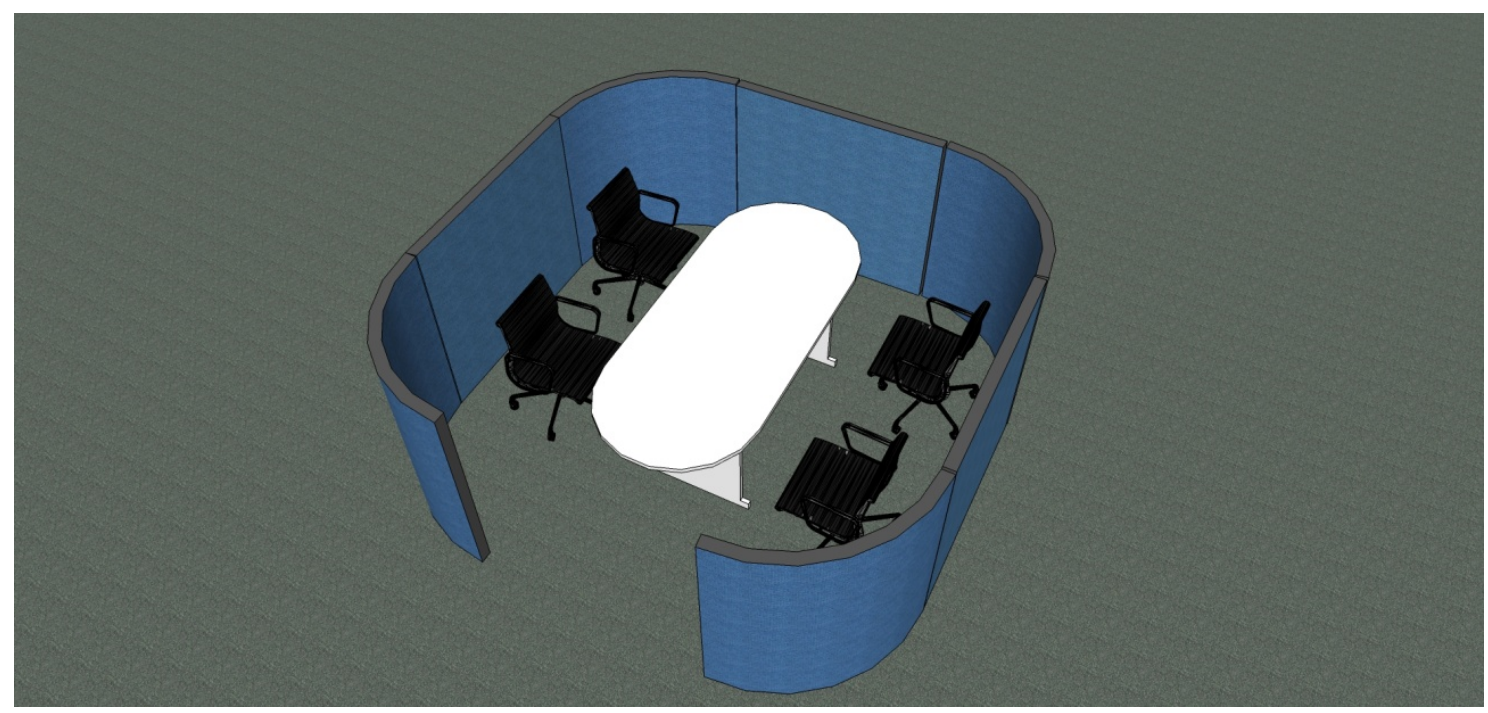

FIGURE 5:HYV EARLY CONCEPT

This design did not initially include any material or process considerations as the primary focus was to address the functional aspects. The proposed system consisted of two basic panels, straight and curved, from which a variety of configurations could be created to suit open plan office users.

\subsubsection{Refining the concept}

In the next part of the survey we attempted to demonstrate our understanding of the requirements through our digital rendering. The questions we asked attempted to find out whether the concept addressed the problems outlined in the first survey. Moreover, we also wanted to know what aspects of this concept would stop customers from purchasing it and what they thought was a fair price range.

The majority of respondents did not think the concept captured the requirements in the first part; however a small subset of respondents liked the concepts, one of these 
being Creative $\mathrm{HQ}$, this indicated a niche market that could be targeted with the first version of Hyv.

\subsubsection{Creative HQ}

Creative HQ is the Wellington region's business incubator, housing some of the most innovative start-ups identified for their potential high growth. We contacted their property manager, Rebecca Hill, to take part in our survey. Rebecca's feedback stood out from the rest; she indicated a strong correlation between our early concept and the requirements of the Creative HQ office. To find out why her feedback was so different, we followed up with a meeting at the Creative HQ office. We learnt that currently their work stations are separated into cubicles using aluminium-frame partitioning. Teams used a central table to host informal meetings and other collaborative activities.

Creative $\mathrm{HQ}$ is contemplating an open plan office when they relocate to a new office in 2014. They require an open plan set up with semi-private spaces that teams can use for meetings, collaboration and other activities, to avoid disruption to people working at their desks.

Rebecca expressed her need for an affordable, simply installed, customisable solution that can be configured in various spaces. She proposed an opportunity to fit-out The Lightning Lab (a three month business accelerator program which Creative HQ supports) to refine the product and provide proof of the concept's functionality. Following that, she foresaw potential for the team to be involved in the Creative HQ fit out in 2014.

\subsection{Prototyping}

Having assessed user responses to the digital concept, work began developing a full scale prototype that would allow interaction with the space and test its performance. Material and processes were considered that would allow the team to build this prototype, using an adaptation of Lean Startup Minimum Viable Product (MVP) theory, with the aim of gathering the most validated learning from the least investment. By quickly creating a full scale, low cost model that could be shown to, 
and interacted with, by users we aimed to quickly establish what aspects of form and function were most critical to the products success.

Cardboard panels were settled on as a suitable material for these early prototypes, as for a modest expense we could create lightweight, self supporting structures that were robust and easily modified. While initially cardboard was proposed purely as a prototyping material it quickly became apparent that it had some permanent potential, particularly as a substrate upon which to apply a range of finishes and coverings. The fundamental physical characteristics of the material are well suited to the requirements of the proposed system and its sustainability and recyclability fitted our ethical position as an enterprise.

\subsubsection{DoubleEco cardboard panels}

DoubleEco is a Wellington business that manufactures cardboard pallets suitable for freight and storage. Cardboard pallets can withstand large loads, do not require fumigation and can be recycled at the end of their useful service life. The corrugated card used by DoubleEco is locally manufactured from sustainably grown wood fibre and glued together with non-toxic adhesive.

\subsubsection{Bending cardboard}

The curved elements of the initial concept provided a point of difference and a degree of aesthetic variation to what was in effect a very simple panel structure. They were initially proposed, as mentioned earlier, with no consideration of how they would be created. This provided a valuable experience in interdisciplinary product development for the team. 


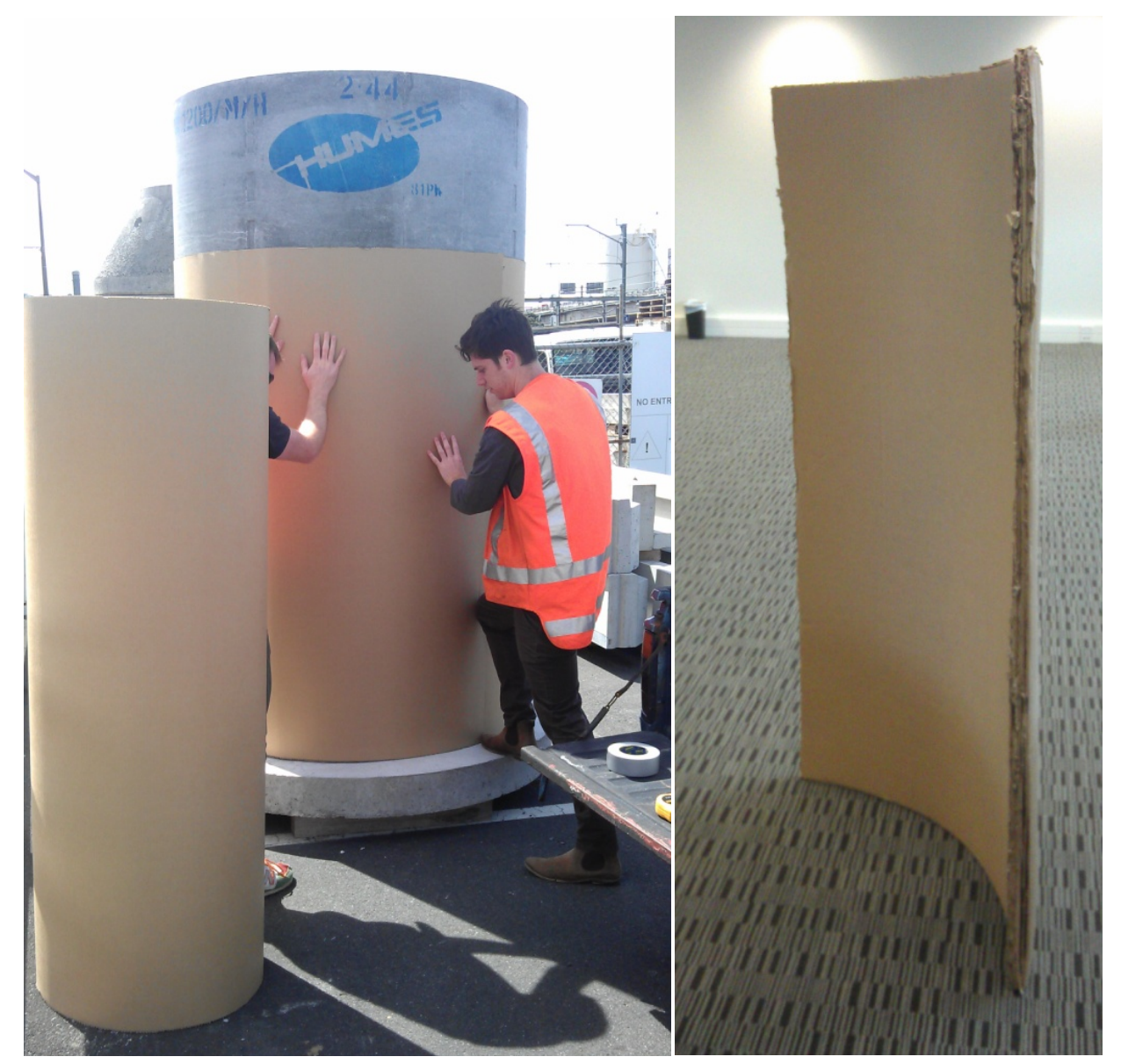

FIGURE 6: BENDING CARDBOARD AND THE FINISHED PANEL

Once again cardboard was well suited to this prototype development. By layering and glueing single layers of corrugated card around a mould (a concrete drain pipe) we were able to create a cardboard cylinder of the required dimensions which was then cut into quarters to create the curved corners of the prototype. This experimentation proved that curved panels could be created relatively easily with a dedicated production process (rather than outdoors round a drain pipe), while providing an indication of the labour (and therefore cost) involved in their creation. The laminated structure is robust and holds its shape well, and provides support to the attached straight panels.

Creating full scale pieces highlighted several issues with curves, in particular the bulk and difficulty of flat packing. Curves also created issues for connecting the panels and, and applying finishes and coverings. 
The second generation of corner panels sought to address the drawbacks of curves while retaining the interesting aesthetic elements, improving configurability and allowing for flat packing. By cutting " $\mathrm{V}$ " grooves into a flat sheet of card we were able to create corners that could be installed in a variety of angles, and laid flat for storage. These are also simpler to connect and cover and can potentially be produced using existing processes without the need for the custom built jigs needed for curved panels.

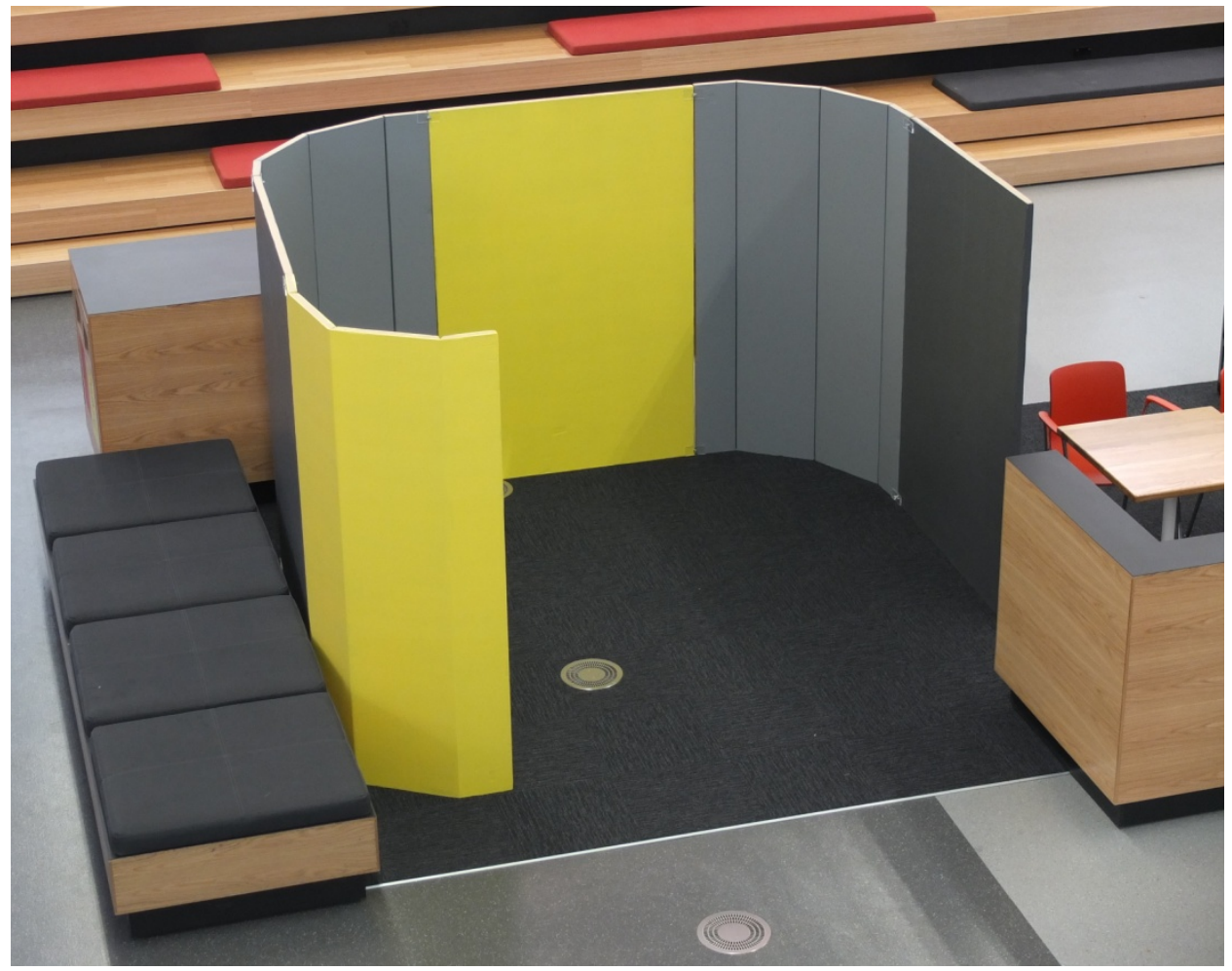

FIGURE 7: HYV1.0 MVP

\subsubsection{Connections}

As customisation, configurability and versatility were important user requirements, the connections that would secure the panels and coverings were crucial and complicated details. To connect two straight panels permanently is relatively straightforward; to do so with a permanently fixed covering (acoustic fabric, decorative prints etc) is also relatively simple. However, to create a connection from scratch that allows for a variety of configurations, repeated tool-less assembly and disassembly, using coverings of different materials and dimensions, while remaining cost effective, very quickly proved to be beyond the capabilities of our team. 
Following this period of frustrated conceptualisation it became clear that we were getting ahead of ourselves. In order to test the concept most functional elements of the prototype could be faked or created in "bare bones" form.

\subsubsection{Coverings and finishes}

Coverings and finishes serve several purposes when applied to the proposed concept: firstly they allow for customisation and variety, allowing the basic units to be matched to colour schemes, themes and branding of the user; secondly coverings can add to the performance of the system, particularly with regard to acoustics.

One of the most spirited team discussions of the year was about whether to cover the cardboard prototype before showing it to potential customers. On one side, some team members felt that that by exposing the bare cardboard structure to the customer we would run the risk of creating an impression of "cheap". Others had the view that covering the cardboard could prove unnecessary if the users did not see coverings and finishes as crucial. In the end the debate boiled down to how we presented the prototype and what we were attempting to test through this customer exposure - whether it was the aesthetics and perceived value, or the core functionality and user interaction attributes.

There was agreement that as completely uncovered panels the cardboard presented poorly. Debate continued over whether to disguise the structure (favoured by the marketing team) or embrace the materiality of cardboard and use its recognisable structure to our advantage (favoured by designers, but more polarising to the customers). A minor breakthrough came with the application of tape to the exposed edges, which hid the corrugations and prevented paper cuts. Suddenly the material began to come into its own as a presentable product.

\subsection{Testing and Feedback}

Having refined our concept and translated the validated digital renderings into a full scale prototype we were ready to show it to a panel of potential users.

In short, the prototype simply consisted of cardboard straight panels and flexible angled corner panels with taped edges and simple acrylic connections. By presenting it 
clearly as an early prototype and encouraging discussion around the pros and cons of the concept we sought to gather a vital body of information from the very people we hoped the system would appeal to.

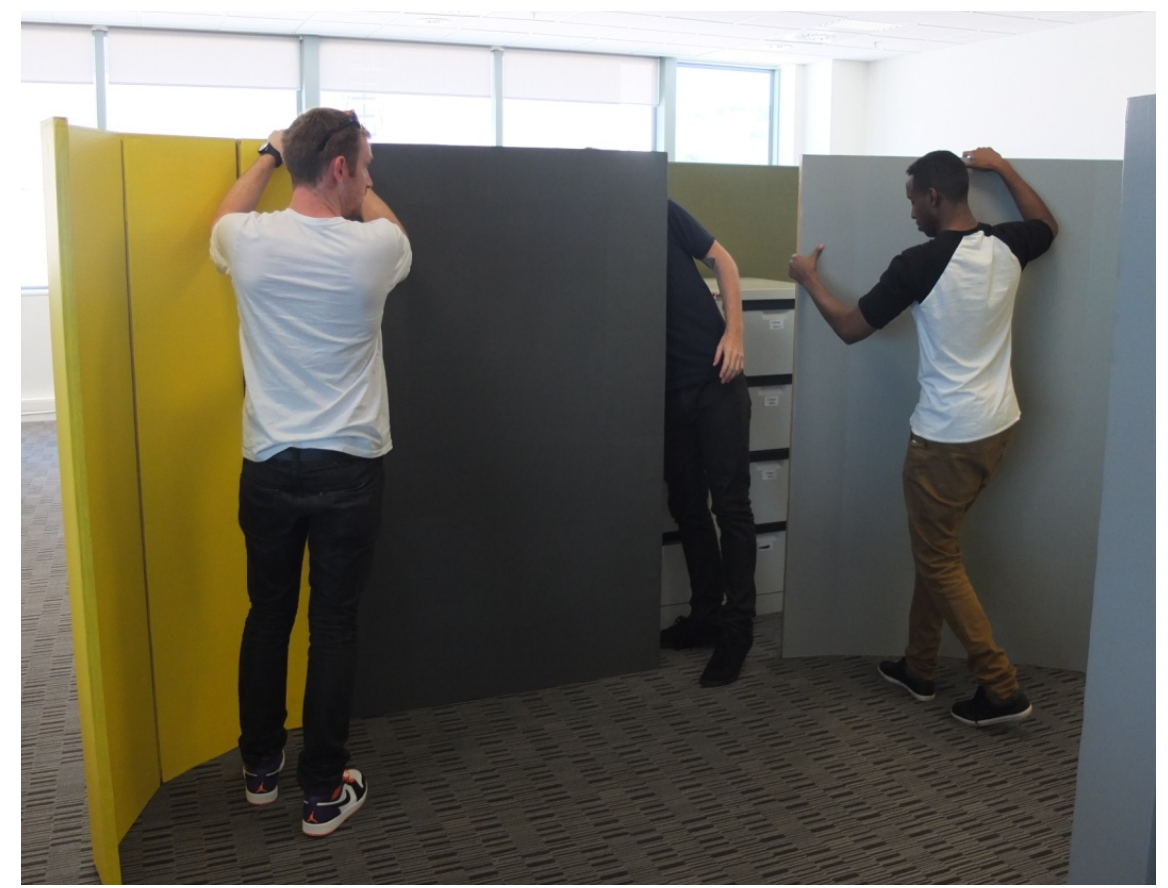

FIGURE 8: INSTALLING THE HYV1.0 PROTOTYPE

\subsubsection{Design School Workshop}

The team organised a showcase event for our network of potential customers where they could experience the prototype, set up in a space at the VUW School of Design. Up to this point most potential customers had only seen the digital renderings. This was a chance to further refine the product's specifications. Customers invited to participate in the showcase were informed beforehand that this was not a presentation of a final product or even the final prototype. Rather this was a chance for them to tell us whether we had understood their requirements correctly. Internally, we also viewed this as an information gathering exercise by setting out the following key objectives.

- Refine the physical features including;

○ dimensions

○ height

- configurability (and reconfigurability) 
- Confirm the intended use and furniture fitting.

- Clarify performance related features i.e. acoustics, level of perceived privacy and whether this was fit-for-purpose in terms use as a meeting room.

- Clarify our understanding of what customers think of the cardboard material, covering options and functional add-ons (whiteboards, pin boards etc.).

- Get an indication of what price people would pay for a finished version.

Key feedback on the Hyv1.0 prototype from the Design School showcase:

- It would be useful for cell phone calls and informal meetings of 3-4 people

- 1.8 metres good for visual privacy, although significant variation in responses

- Cardboard should be covered for a more "professional" look, although some users appreciated the funky cardboard aesthetic

- Strong interest in being able to move, reconfigure and store the product easily, though unlikely to occur frequently

- Some interest in users being able to customise a "basic" model

- Would suit informal furniture, coffee tables etc. Formal meetings can happen in the board room

- General acceptance of $\$ 900.00$ for a basic "booth"

- General surprise at the decent level of acoustic separation between two showcase booths

\subsubsection{Summary}

The majority of the respondents expressed interest in the Hyv1.0 solution for informal meetings of roughly three people. The heights of the panels were deemed appropriate by the customers for the purpose of use. Participants also indicated the need for affordable pricing, which in the end was closely aligned with our cost predictions. Use of cardboard panels did not significantly detract from the concept, although covering it with a more aesthetically appealing material would be the preferred in a corporate environment, regardless of cost. Furthermore, the results point to the importance of the ability to reconfigure the system in various spaces, while also indicating the likely frequency rate of reconfiguring the meeting rooms is not as high as we had expected. 
The results indicate a market opportunity for an affordable, simple to install and easily configured partitioning system that can be used to create a variety of semi-private meeting spaces. This market is characterized by organizations who are seeking a temporary solution, most probably while they look for a new, permanent office space. Based on our research there is a strong indication that this is a niche market. Therefore the current Hyv1.0 MVP is unlikely yield a highly profitable business that can employ all of the founding members on full-time basis. Exploring a more permanent solution based on the same concept is one interesting avenue to explore further as feedback indicates a bigger market. Extensive market validation is required to confirm if there is indeed a market for a 'permanent' version of Hyv.

\subsection{Promotion and Branding}

At this stage in the project we decided to execute some promotional initiatives, to actively spread the word about our team work. We created a temporary landing web page and experimented with using Google Adwords in an attempt to drive traffic to the site and to gain the email addresses of interested parties.

We engaged graphic designers Nandini "Nanz" Nair and Rose Wu from GoodieTwo to create a brand identity around "Hyv" for promotional materials and for use on social media sites.

The designers' brief focussed on our business entity and the customer benefit we sought to create - productive meeting spaces in busy environments - rather than branding a specific product. Our hope was that companies would eventually refer to a meeting room or meeting space as a "Hyv".

The team had discussed names that would suggest the benefits of the product (creating productive, quiet meeting spaces in busy environments), such as cocoon, hub, hive, shell, etc. We settled on the name 'Hive' as it suggested a productive working space, this subsequently became Hyve, then Hyv.

With the brand identity in place and the latest version of the prototype built, we began creating promotional materials to enable us to communicate the value to customers. After previous discussions with a number of potential customers, we 
understood what benefits, features and wording to use in targeting their interest. The designers created a brochure that sought to communicate the key benefits of the product. It also sought to catch the attention of customers through its innovative design. The brochure was folded in a way which resembled the panel product that we had produced. That enabled multiple brochures to be assembled to create variations of meeting rooms. This brochure achieved and demonstrated the core characteristics of the product: "flexible, lightweight, reconfigurable, versatile and simple".

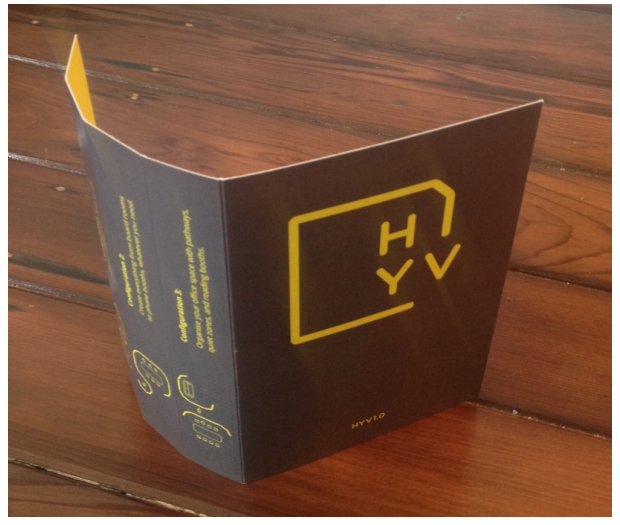

FIGURE 9: HYV BROCHURE SHOWING BRANDING

\subsection{Summary: Lessons Learned}

- A user-centred, iterative product development process highlights whether the project is on the right track as early as possible.

- It is never too early or too late to include the customer in the product development process.

- Office workers and managers recognise value in what Hyv1.0 is aiming to achieve, however the form of the prototype has room for improvement. 


\section{Chapter 5 Hyv2.0}

At present the Hyv project is based around the team's understanding of the need for furniture solutions that address issues of privacy and acoustics in open plan offices. Our prototype - Hyv1.0 - has shown potential as a concept for addressing these issues but requires substantial refinement.

\subsection{Necessary next steps}

In order to develop Hyv as a business, several key activities are necessary.

- Product Development: The current prototype requires significant development to become a product as either a cardboard MVP, or to develop into a more substantial "permanent" product. This development requires product design and engineering input.

- Customer Development: Refining the prototype requires continued development of relationships and communication with potential users who will ideally become customers.

- Business Development: As the project makes the transition from academic project to independent business, the ongoing structure of the entity must be determined. This relies on the commitment of the team to continue development, which itself relies on the underlying potential of the current concept.

\subsection{Development Plan}

As the team will no longer be students, the economics of continuing to develop the Hyv system take on new importance in 2014. The ideal situation is to generate early revenue to fund further development; this is where the minimum viable product technique becomes truly valuable.

\subsubsection{The Lightning Lab MVP}

The MVP, as distinguished from the prototype, is the first version of the product that we hope to sell to a paying customer. While the MVP may not include every function 
proposed it does include those features most critical to success in order to meet the requirements of a particular user (the early adopter) to the point where they are ready and willing to spend money on it.

The second annual Lightning Lab business accelerator program will run in Wellington from March to May 2014. As a short term entity incorporating a number of autonomous startup businesses the Lab has a fairly unique set of office fit out requirements. We are in discussions to provide cardboard Hyv1.0 breakout spaces to the Lab to allow teams collaborative spaces where they can get together for meetings, Skype calls or to escape their desks for a spell.

\subsubsection{Tertiary Education Commission}

Following the December MATE presentation the Hyv team were approached by Chris King, Manager of corporate support projects and services at the Tertiary Education Commission (TEC), to discuss the potential of trialling the Hyv1.0 prototype. Chris was intrigued by the concept and wants to explore options for an upcoming re-fit of the TEC offices. The new space will be largely open plan and will require configurable spaces to provide staff with space to collaborate. The trial has been confirmed for two months beginning in March 2014. This will allow a fresh look at the concept and the prolonged trial will allow the TEC staff to experiment with the system and provide valuable feedback which we can use to iteratively improve it.

Following this trial, we will hopefully have a completely validated concept specifically tailored to a particular customer. While this will not necessarily translate into a repeatable product the opportunity to create part of the TEC fit out would be a revenue generating process that could ultimately support the continuation of the business.

\subsection{Manufacture / Licensing potential}

Should the TEC trial prove successful, the team will look to outsource production of the product. As a startup business Hyv lacks facilities and equipment for in-house manufacture. Further, the skill sets of the team members are better suited to validation, research and sales than manufacture. 


\subsubsection{Formway Design Connection}

We have established a relationship with Formway Design, a local business who have built a global presence in the field of furniture design. Formway no longer manufacture their designs in house, instead licensing them to established international manufacturers and thereby gaining support and exposure to a global market. This is a hugely relevant model for us as a business as we would seek to follow a similar path in order to broaden our market without going head to head with established players. Formway have offered to provide feedback from a mentorship position for the ongoing product development work. This is invaluable experience and further reinforces the learning and process we have undertaken through the MATE programme in taking a concept from academic roots towards commercial realisation.

\subsection{Texus Fibres Collaboration}

Through VicLink Hyv came in contact with Timothy Allan of Locus Research, a Tauranga based market research and product development company. Timothy is on the board of Texus Fibres, a manufacturer of non-woven coarse wool fabric (felt) who are looking to find applications for their material.

As well as being a locally produced renewable material with a high level of aesthetics, Wool has excellent acoustic properties and the potential for passive air filtration, meaning that it has the ability to trap and store harmful vapours which are off-gassed by some building materials and furniture.

Initial market validation has shown that there is growing awareness of issues around air quality in response to sick building syndrome, and by combining our concept for highly reconfigurable office furniture with acoustic control and improved air quality we believe we have a unique value proposition with wide ranging applications, however this is a hypothesis that is yet to be fully tested.

\subsubsection{Tech Jumpstart Summer Project}

We have a Memorandum of understanding with Texus fibres for material supply and process assistance to develop a prototype based on our market research that will 
explore the use of wool fabric in acoustic furniture. Our work will include exploration of methods of forming Texus material into rigid three dimensional structures that could be built into self supporting structures, applied as panelling to ceilings and walls or used in conjunction with the Hyv1.0 system to improve the acoustic performance.

This work is ongoing thanks to a grant from VicLink and KiwiNet via the Tech Jumpstart summer programme. This funding has allowed us to engage the services of recent graduate industrial designers James Bennett and Lucy Mangin to work on the Texus collaboration and fine-tuning the cardboard prototype.

\subsection{Overall Viability}

Our research has shown that there is a market driven opportunity to develop furniture-based versatile work spaces for open plan offices. Potential users have expressed genuine interest in our concept; however significant development is required to get the current prototype to a finished product.

Our work has identified a business opportunity based on the design and manufacture of commercial furniture-based products. While this model has potential for growth it is unlikely to present a case for significant investment and would be better suited to development by a founding team with appropriate technical skills.

Further product development in conjunction with established market contacts will determine the ultimate viability of the current Hyv concept. As the physical form of the product is refined, the viability of the business model will become clearer. 


\section{Chapter 6 Conclusions}

\subsection{Ish - Overall Lesson Learned}

One of the key learning outcomes for me this year is the importance of starting with a clear vision as a tool to guide the enterprise development. Over the course of the year we worked on different projects, pivoted several times with some projects and experienced moments when there wasn't a clear path we should take next. Having a clear vision of what we wanted to achieve from the outset would have been quite valuable as we progressed through the many changes we experienced. While changes are inevitable in highly uncertain environment, such as a start-up, having a clear and consistent overarching vision that binds expectations and helps the team move forward as unit can make huge difference.

\subsection{Liam - Overall Lesson Learned}

An important lesson that I have taken away from this experience is the benefit of using thorough market research and customer feedback to define both products and projects early on in the development process, long before turning to prototypes and building products. More accurately defined projects and products have fewer complications in later stages of their development and are less likely to result in products that customers do not want. Getting a user-defined product specification right requires a lot of up front work, but ultimately leads to more successful ventures in the long run.

\subsection{Ian - Overall Lesson Learned}

Continuous customer feedback - a key learning for the team this year was the importance of maintaining active relationships with our prospective customers. The process of market validation does not stop after the initial contact. We learnt that it is important to involve the prospective customer within the product development process. We were able to make iterative adjustments to our prototype and overall business strategy after conferring with customers and gaining further feedback. We 
also found that building this type of relationship with a customer would encourage them to become invested in the success of the product.

\subsection{Oliver - Overall Lesson Learned}

In order to successfully commercialise ongoing research projects, interdisciplinary MATE teams require strong support and direction from the research team to compensate for a lack of internal domain knowledge. Alternatively, in order to build experience of entrepreneurship through startup enterprises and resultant constructive failures, teams need complete autonomy and freedom to develop opportunities they have identified themselves and are therefore hopefully able to generate momentum and belief in the value of the venture. Either way it must be understood and accepted that academic research and commercial enterprises do not always share common objectives. Therefore, commercialisation teams must be prepared to pivot, adapt and occasionally walk away from projects as they search for the elusive viable business model. 


\section{References}

Andreae, H (2013) Masters of Advanced Technology Enterprise Project Submission Form.

Blank, S.G. (2007) The Four Steps to the Epiphany. Foster City: CafePress

McGrath, K. (2013) Masters of Advanced Technology Enterprise Project Submission Form.

Osterwalder, A. \& Pigneur, Y. (2010) Business Model Generation. Hoboken: Wiley Perkins, N. (2013) Masters of Advanced Technology Enterprise Project Submission Form

Ries, E. (2011) The Lean Startup. New York: Crown Business

Williams, G (2013) Masters of Advanced Technology Enterprise Project Submission Form. 